\title{
ANTE LA ENCRUCIJADA DEL NO DERECHO Y LA EXCEPCIÓN PENAL NORMALIZADA: UNA REFLEXIÓN CRÍTICA Y PROPOSITIVA A PARTIR DE LA SITUACIÓN ACTUAL DE LOS «COMBATIENTES TERRORISTAS EXTRANJEROS» EUROPEOS ${ }^{1}$
}

\author{
Carlos Fernández Abad y Julia Ropero Carrasco \\ Universidad Rey Juan Carlos
}

Title: Facing the crossroads of non-law and the standardized criminal exception: a critical and purposeful reflection on the current situation of the European Terrorist Fighters

\begin{abstract}
Sumario: 1. Introducción; 2. El problema de los retornados: una aproximación a las causas que explican la posición de rechazo de los países europeos; 3 . Tres tipos de respuestas posibles: un alegato en favor de la repatriación activa de los «combatientes terroristas extranjeros»; 4. Una paradoja llamativa: ¿reclamando la aplicación de un «Derecho Penal del enemigo» para proteger los derechos humanos?; 5. Conclusiones
\end{abstract}

Resumen: Los autores de esta artículo examinan la situación actual de los «combatientes terroristas extranjeros» procedentes de la Unión Europea y la política basada en el desentendimiento de sus nacionales y la preferencia de que estos sean juzgados en Siria e Irak que, en su inmensa mayoría, están siguiendo los países europeos. En este sentido, se enarbola una reflexión crítica y propositiva en la que se sugiere que, tanto desde un punto de vista que priorice la seguridad por encima de todo

${ }^{1}$ Este trabajo forma parte de los resultados obtenidos en el Proyecto de Investigación Nacional «La RES 2178 de UN y su trasposición a los derechos penales nacionales: propuestas de equilibrio entre la seguridad y los derechos individuales» (DER2016-77838-R), financiado por el Ministerio de Economía y Competitividad, en el que participan sus autores. 
como en lo que se refiere exclusivamente a la protección de los derechos humanos, la repatriación activa de estas personas y su enjuiciamiento en los países de origen es la opción más aconsejable.

Palabras Clave: Terrorismo; «combatiente terrorista extranjero»; repatriación activa; Derecho Penal.

Abstract: The authors of this paper address the current situation of the «foreign terrorist fighters» from the European Union and the policy essentially based on the detachment of their nationals and the preference for them to stand trial in Syria and Iraq which, in their vast majority, European countries are following. In this vein, a critical and propositional reflection is raised in which it is suggested that, both from a point of view that prioritizes security above all else and in what refers exclusively to the protection of human rights, active repatriation of these people and their prosecution in the countries of origin is the most advisable option.

Keywords: Terrorism; «foreing terrorist fighter»; active repatriation; Criminal Law.

\section{Introducción}

A raíz de la emergencia y escalada de los conflictos en Siria e Irak desde el año 2011, el fenómeno de los «combatientes terroristas extranjeros» ha adquirido una especial relevancia y visibilidad en el seno de las políticas antiterroristas de los países occidentales ${ }^{2}$. A pesar de no

2 Bures, O. «Eu's Response to Foreing Fighters: New Threat, Old Challenges?», Terrorism and Political Violence, 2018, p.1. En este sentido, sirva como ejemplo que, en el caso español, la Estrategia Nacional Contra el Terrorismo advierte que «uno de los mayores retos a los que se debe hacer frente es el fenómeno de los combatientes terroristas extranjeros, especialmente, la proliferación de los retornados desde escenarios de conflicto» (GOBIERNO DE ESPAÑA. Estrategia Nacional contra el Terrorismo. Madrid, Ministerio de la Presidencia, Relaciones con las Cortes e Igualdad, 2019, p. 19). Ahora bien, conviene advertir que, tal y como sucede con otros conceptos hegemónicos dentro de los estudios de terrorismo, el término de "combatiente terrorista desplazado» ha sido ampliamente discutido por la literatura científica y especialmente desde el Derecho Internacional. Sobre esta cuestión, véase a modo de ejemplo, Schmid, A. «Foreing (Terrorist) Fighters Estimates: Conceptual and Data Issues», International Centre for Counter-Terrorism-The Hague, 2015, pp.3-6; MALET. D. «Foreing Fighter Moblization and Persistence in a Global Context», Terrorism and Political Violence, 2015, pp.1-20; JimÉNEZ GARcía, F. «Combatientes Terroristas Extranjeros y conflictos armados: utilitarismo inmediato ante fenómenos no resueltos y normas no consensuadas», Revista Española de Derecho Internacional, vol.62/2, 2016, pp.277-301 y MARRERO RocHA, I. «Los combatientes «terroristas» extranjeros de la Unión Europea a la luz de la Resolución 2178 (2014) del Consejo de Seguridad de Naciones Unidas», Revista de Derecho Comunitario Europeo, 2016, núm.54, pp.555-594. En estos términos, en este artículo se sigue la definición esgrimida por el Consejo de Seguridad de Naciones Unidas en su Resolución 2178 (2014). Es decir, los «combatientes terroristas extranjeros» serían «las personas que viajan a un 
resultar un fenómeno particularmente novedoso ${ }^{3}$, diferentes autores han coincidido en señalar la concurrencia de ciertos elementos que dotan a esta oleada de una especial significancia con respecto a sus anteriores manifestaciones ${ }^{4}$. En este sentido, se ha sostenido que el reciente conflicto sirio ha provocado una movilización de personas mucho más rápida y masiva que sus expresiones precedentes ${ }^{5}$, teniendo muchas de ellas como destino final la integración en una organización terrorista ${ }^{6}$. En estos términos, se calcula que, desde que estalló la guerra civil siria, el número de «combatientes desplazados» se ha situado en valores comprendidos entre las 35.000 y 40.000 personas $^{7}$. Por otra parte, aunque la inmensa

Estado distinto de su Estado de residencia o nacionalidad con el propósito de cometer, planificar o preparar actos terroristas o participar en ellos, o de proporcionar o recibir adiestramiento con fines de terrorismo» (RESOLUCIÓN 2178 (2014) de 24 de septiembre de 2014, S/RES/2178, p.2).

3 En este sentido, POKAlova identifica la existencia de grandes tres oleadas previas: en primer lugar, la guerra soviético-afgana (1979-1989) habría generado una importante movilización de combatientes extranjeros, mayoritariamente procedentes de países árabes. Posteriormente, una vez finaliza este conflicto y fundamentalmente a partir de los años noventa, algunas de estas personas que habían participado en la resistencia afgana viajaron a otras zonas -por ejemplo, Argelia, Bosnia, Chechenia, Filipinas o Somalia- para participar en conflictos regionales y realizar la yihad. En tercer lugar, la invasión de Irak por parte de EE. UU en 2003 habría dado lugar a una tercera gran movilización. Para un mayor desarrollo de cada una de las oleadas, véase, PoKALova, E. Returning Islamist Foreing Fighters. Threats and Challenges to the West, Switzerland, Palgrave Macmillan, 2020, pp.11-39. En referencia al número total de combatientes movilizados durante estas tres primeras oleadas, se calcula un valor aproximado de 30.000 personas (ScHmID, A. «Foreing (Terrorist) Fighter Estimates: Conceptual and Data Issues», op. cit., p.1). Sin embargo, conviene destacar que el fenómeno de los combatientes extranjeros es un fenómeno mucho más amplio que en ningún caso se limita al mundo árabe. En este sentido, suele ser citado como ejemplo paradigmático la gran movilización -entre 35.000 y 50.000 personas- que estimularon las Brigadas Internacionales en el contexto de la Guerra Civil Española. Para una comparativa entre ambos fenómenos, véase TAммIKo, T. (2018). «The Threat of Returning Foreing Fighters: Finnish State Responses to the Volunteers in the Spanish and Syria-Iraq Civil Wars», Terrorism and Political Violence, 2018, pp.1-18.

4 Entre otros muchos, véase, por ejemplo, VIDINO, L. «European foreing fighters in Syria: dynamics and responses», European View, núm.13, 2014, pp.217-224; GARCÍA-CALVO, C. "No hay vida sin yihad y no hay yihad sin hégira: la movilización yihadista de mujeres en España, 2014-2016», Real Instituto Elcano, Ari 28/2017, 2017, p.2; BurES, O. "Eu’s Response to Foreing Fighters: New Threat, Old Challenges?», op. cit., pp.1-19.

5 PoKalova, E. Returning Islamist Foreing Fighters. Threats and Challenges to the West, op. cit., p.40.

6 Fundamentalmente, el DAesh y Al-Nusra (MARrero Rocha, I. «Los combatientes «terroristas» extranjeros de la Unión Europea a la luz de la Resolución 2178 (2014) del Consejo de Seguridad de Naciones Unidas», op. cit., p.563).

7 Sobre esta cuestión, merece la pena destacar que el flujo de combatientes terroristas desplazados desde que estalló el conflicto sirio hasta la actualidad no ha sido ni mucho menos homogéneo. En este sentido, PoKalova identifica varios momentos diferentes: por una parte, el primero de ellos estaría compuesto principalmente tanto por combatientes que habían participado previamente en otros conflictos como por individuos inspirados por la denominada "primavera árabe», no siendo especialmente numerosa. Por otra parte, la autora constata la existencia de un segundo momento que genera una movilización mucho más nutrida que se extiende desde finales del 2012 y engloba a individuos 
mayoría de ellos han sido musulmanes sunnís procedentes del mundo árabe $^{8}$, otro aspecto destacado de esta oleada ha sido la elevada cifra de individuos que provienen de países occidentales, entre los que se encuentran al menos 5.684 ciudadanos de la Unión Europea ${ }^{9}$. Este hecho, por su parte, ha sido interpretado por los diferentes Estados Miembros como una importante amenaza a la seguridad al advertir la posibilidad de que, cuando retornen, estas personas puedan participar en actos de terrorismo doméstico ${ }^{10}$. Por último, debido fundamentalmente a la proclamación del Califato en el año 2014 y a la vasta extensión de territorio que llegó a controlar el DAESH ${ }^{11}$, otro aspecto distintivo residiría en el hecho de que, si en las oleadas precedentes el único motivo del viaje era participar en el conflicto bélico o, en su defecto, recibir entrenamiento militar, ahora también se habrían desplazado individuos y familias enteras con la única pretensión de convertirse en ciudadanos del autodenominado Estado Islámico ${ }^{12}$.

procedentes de 74 países diferentes, estando sobre todo marcado por la existencia de una fuerte propaganda yihadista. La proclamación del Califato, sin embargo, habría dado lugar a un tercer momento que genera una oleada mucho más numerosa que, por su parte, no solo se ha nutrido de personas con la voluntad de participar en el conflicto bélico sino también de otras con la intención de asentarse en el territorio y convertirse en ciudadanos del Estado Islámico. Por último, fundamentalmente como consecuencia de la paulatina pérdida de territorio y las derrotas militares experimentadas, así como de las restricciones impuestas por los países para impedir estos viajes a las zonas de conflicto y la existencia de un mayor control en la frontera turca, se habría producido un descenso continuado en el número de combatientes terroristas desplazados (Pokalova, E. Returning Islamist Foreing Fighters. Threats and Challenges to the West, op. cit., pp.48-54).

8 Byman, D. «The homecomings: What Happens When Arab Foreing Fighters in Iraq and Syria Return», Studies in Conflict and Terrorism, vol.38, 2015, núm.8, p.2.

9 PoKalova, E. Returning Islamist Foreing Fighters. Threats and Challenges to the West, op. cit., p.42. EUROPOL, por su parte, sitúa está cifra en aproximadamente 5.000 personas, siendo Bélgica, Francia, Alemania y Reino Unido los países más afectados (EUROPOL. «European Union Terrorism Situation and Trend Report 2019», European Union Agency for Law Enforcement Cooperation, 2019, p.40). En lo que se refiere de forma específica al caso español, se calcula que se habrían trasladado a estas zonas de conflicto a partir del año 2012 entre 230 y 235 personas (REINARES, F. «Yihadistas retornados tras desplazarse de España a Siria e Irak: ¿qué motivos tienen?, ¿dónde están ahora?, ¿suponen un peligro», Real Instituto Elcano, Comentario Elcano 50/2018, 2018, p.1).

10 Boutin, B., Chauzal, G., Dorsey, J., Jegerings, M., Paulussen, C., Pohl, J., Reed, A., ZaVaGLI, S. «The Foreing Fighters Phenomenon in the European Union», International Centre for Counter-Terrorism-The Hague, ICCT Research Paper, 2016, p.14

11 Sobre esta cuestión, se calcula que, para finales del año 2014, el DAESH controlaba un área de 88.000 kilómetros cuadrados que, estando habitada por cerca de ocho millones de personas, se correspondería con una tercera parte de Irak y la mitad de Siria (DE LA CORTE IBÁŃEZ, L. «Un califato sin territorio ni califa. Vida y muerte de Bagdadi y sus consecuencias para el futuro del Daesh y la yihad global», Instituto Español de Estudios Estratégicos, Documento Marco 13/2019, 2019, p.9)

12 En este sentido, desde que al-Baghdadi proclamó el Califato en el año 2014, una de las consignas más repetidas por la propaganda yihadista ha sido incidir en la obligación que tiene todo musulmán de emigrar a las tierras del Islam. Como consecuencia, otro aspecto distinto de esta oleada con respecto a sus anteriores manifestaciones ha sido su capacidad para movilizar también a las mujeres (GARCíA-CALVO, C. «No hay vida sin yihad 
En este contexto, precisamente, debe ser situada la RES 2178 (2014) del Consejo de Seguridad de Naciones Unidas, en la que, expresando una grave preocupación por la amenaza que representan los «combatientes terroristas extranjeros», tanto en lo que se refiere a su capacidad para aumentar la intensidad y duración de los conflictos como al potencial peligro que suponen para los países de origen, tránsito y destino, se insta a los Estados a desarrollar una respuesta integral que, entre otras medidas, abarque cuestiones relacionadas con prevenir la radicalización que conduce al terrorismo, frenar el reclutamiento, dificultar los viajes de los combatientes terroristas extranjeros, obstaculizar el apoyo financiero a estas personas y facilitar su reintegración y rehabilitación social ${ }^{13}$. Por su parte, tres años más tarde, la Directiva (UE) 2017/541 relativa a la lucha contra el terrorismo también ha incidido en la relevancia de este fenómeno al advertir que los «combatientes terroristas extranjeros» representan una importante amenaza para todos los Estados Miembros, aludiendo en su artículo noveno a la exigencia que tienen estos de tipificar en sus legislaciones nacionales el hecho de viajar al extranjero con la finalidad de cometer o contribuir a la comisión de un delito de terrorismo, participar en las actividades de un grupo terrorista o recibir adiestramiento. Asimismo, en el artículo 10 de la Directiva, también se conmina a los Estados a adoptar las medidas necesarias para que también se tipifique como delito todo acto de organización o facilitación con el que se ayude a cualquier persona a viajar con fines terroristas ${ }^{14}$.

En este sentido, según se ha ido haciendo palpable la amenaza que representan los "combatientes terroristas extranjeros», los países occidentales han ido tomando diferentes medidas que, en términos generales, pueden ser divididas entre aquellas que estarían orientadas a evitar que sus nacionales viajen a estas zonas de conflicto y las que, en sentido opuesto, estarían dirigidas a impedir que, aquellos que ya se encuentran en estos territorios, retornen a sus países de origen ${ }^{15}$. En relación con las primeras, estas han abarcado desde medidas como retirar o confiscar los documentos de viaje a la elaboración de listas de pasajeros con la finalidad de que las autoridades competentes puedan detectar e impedir la

\footnotetext{
y no hay yihad sin hégira: la movilización yihadista de mujeres en España, 2014-2016», op. cit., p.2).

13 Resolución 2178 (2014) de 24 de septiembre de 2014, S/RES/2178, p.2. Posteriormente, el Consejo de Seguridad de Naciones Unidas ha vuelto a manifestar su preocupación en relación con los «combatientes terroristas desplazados» e instado a que los Estados tomen medidas en la Resolución 2253 (2015) y la Resolución 2396 (2017).

14 Directiva (UE) 2017/541 del Parlamento Europeo y del Consejo de 15 de marzo de 2017 relativa a la lucha contra el terrorismo y por la que se sustituye la Decisión maco 2002/475/JAI del Consejo y se modifica la Decisión 2005/671/JAI del Consejo.

15 PoKalova, E. Returning Islamist Foreing Fighters. Threats and Challenges to the West, op. cit., pp.111 y ss.
} 
salida de sus ciudadanos del territorio nacional ${ }^{16}$. Asimismo, ya sea a través de un tipo específico o subsumiéndolo en otros, también se ha procedido a la criminalización de los «combatientes terroristas extranjeros» ${ }^{17}$. Sobre esta cuestión, Pokalova advierte que tal criminalización no debe ser observada únicamente desde un prisma represivo sino que, al mismo tiempo, esta ejercería una importante función preventiva ya que, ante la amenaza de sanción, podría disuadir a algunas personas de trasladarse a estas zonas de conflicto ${ }^{18}$. Por último, en un plano más general y como parte integrante de una estrategia integral, algunos países también han adoptado medidas preventivas que, empleando otros instrumentos que anteceden y trascienden al Derecho Penal, han estado principalmente enfocadas a luchar contra el extremismo violento ${ }^{19}$.

En referencia a las segundas -es decir, aquellas medidas que estarían orientadas a impedir que los «combatientes terroristas extranjeros» retornen a sus países de origen-, Pokalova advierte que, aunque raramente ha sido explicitada como parte de la estrategia oficial por motivos evidentes $^{20}$, algunos países occidentales -entre otros, Estados Unidos, Reino

16 En este sentido, PoKalova cita como ejemplo paradigmático el caso francés, donde las autoridades, siempre que exista una sólida creencia que el individuo va a realizar este viaje para participar en una organización terrorista, pueden prohibir que salga del país mediante la confiscación del pasaporte. En el caso de Reino Unido, en una línea similar, los servicios de seguridad pueden retener el pasaporte del individuo en cuestión en los puestos de frontera por un periodo de 14 días, hasta una extensión máxima de 30. Para un mayor detalle de estas medidas y otras similares en otros países, véase, PoKALOVA, E. Returning Islamist Foreing Fighters. Threats and Challenges to the West, op. cit., pp.112 y ss. y Boutin, B. «Administrative Measures against Foreing Fighters: In Search of Limits and Safeguards», International Centre for Counter-Terrorism-The Hague, 2016, pp.1-35.

17 En estos términos, tanto la RES 2178 (2014) del Consejo de Seguridad de Naciones Unidas como la Directiva (UE) 2017/541 del Parlamento Europeo y del Consejo han exhortado a los Estados a tipificar el hecho de que sus nacionales viajen o intenten viajar a un Estado distinto de su residencia o nacionalidad con el propósito de cometer, planificar o preparar actos terroristas, así como proporcionar o recibir adiestramiento con estos fines. En referencia específica al caso español, la LO 2/2015 introduce un nuevo delito en el art. 575.3 CP que castiga con una pena de dos a cinco años de prisión a quien, con la finalidad de cometer delitos de terrorismo, se traslade o se establezca en un territorio extranjero controlado por un grupo u organización terrorista. Posteriormente, a través de la LO 1/2019, se elimina esta última referencia a un territorio extranjero controlado por un grupo u organización terrorista, haciendo únicamente referencia el art. 575.3 CP a un «territorio extranjero».

18 PoKalova, E. Returning Islamist Foreing Fighters. Threats and Challenges to the West, op. cit., p.115.

19 Para una revisión detallada y actualizada de estos programas, véase especialmente, KoeHLeR, D. Understanding Deradicalization. Methods, tools and programs for countering violent extremism, New York, Routledge, 2017.

20 Sobre los diferentes problemas que plantean el uso de drones desde el punto de vista jurídico, véase, Gómez IsA, F. «Los ataques armados con drones en Derecho Internacional», Revista Española de Derecho Internacional, vol.67/1, 2015, pp.61-92 y SILVA SÁncheZ, J.M. "Asesinatos selectivos en la "guerra punitiva» contra el terrorismo», InDret. Revista de Análisis para el Derecho, núm.1, 2017, pp.1-19. 
Unido o Francia- han buscado directamente la eliminación física de sus ciudadanos en el campo de batalla mediante el denominado enfoque shoot to kill, ya sea a través de acciones militares directas o a través del uso de drones ${ }^{21}$. Por otra parte, siendo también una medida controvertida, otros han optado por revocar la nacionalidad de sus ciudadanos para impedir el citado regreso ${ }^{22}$. Si bien es cierto que esta opción ha sido mayoritariamente aplicada en supuestos donde la nacionalidad ha sido adquirida o existe una doble nacionalidad, también lo es que, por ejemplo en el caso de Reino Unido, esta medida ha sida extendida a personas que aparentemente no tendrían otra nacionalidad, tornando a la persona afectada en apátrida, con todas las consecuencias que ello conlleva ${ }^{23}$. Por último, aunque no es una medida estrictamente orientada a evitar que los «combatientes terroristas extranjeros» retornen, es importante advertir que, en el caso de que lo hagan, algunos países occidentales han desarrollado programas de reeducación y reinserción social, tanto para personas que, debido a la falta de evidencia, no han sido condenadas

21 Entre los numerosos ejemplos existentes, puede ser citado, por ejemplo, el caso de Reyaad Khan, un ciudadano británico abatido en agosto de 2015 por un dron de las Fuerzas Armadas Británicas cuando se encontraba en Siria. Tras la polémica generada, Theresa May, entonces Primera Ministra Británica, no solo defendió este ataque afirmando que había sido necesario y proporcionado al tomar en consideración la amenaza inminente que representaba esta persona para Reino Unido, sino que, además, también afirmó que volvería a autorizar más ataques de este tipo en el futuro (MACASKILL, E. «May defends use of drones to kill British terrorist overseas», The Guardian, 20 de diciembre de 2017, Disponible en [fecha de última consulta: 20 de mayo de 2020] https:/www.theguardian. com/world/2017/dec/20/theresa-may-drone-strikes-british-terrorists-reyaad-khan).

22 Mehra, T. «European countries are being challenged in court to repatriate their foreing fighters and families", International Centre for Counter-Terrorism - The Hague, Disponible en [fecha de última consulta: 21 de mayo de 2020] https://icct.nl/publication/ european-countries-are-being-challenged-in-court-to-repatriate-their-foreign-fightersand-families/

23 El ejemplo más recognoscible y mediático dentro de este último supuesto es el caso de Shamina Begum, una joven ciudadana británica que abandonó Londres para desplazarse a Siria y convertirse en ciudadana del autodenominado Estado Islámico. Recientemente, esta solicitó poder regresar a Reino Unido con su hijo recién nacido, sin embargo, las autoridades británicas optaron por impedir su retorno a través de la revocación de su nacionalidad, a pesar de no tener ninguna otra. Tras el nacimiento, el bebé falleció mientras Shamina Begum permanecía en un campo de detención en Siria (DE Miguel, R. "La muerte del bebé de una británica del ISIS desata las críticas al Gobierno», El País, 10 de marzo de 2019, Disponible en: [fecha de última consulta: 20 de mayo de 2020] https://elpais.com/internacional/2019/03/09/actualidad/1552138934_514792.html. Las últimas noticias sobre este caso señalan, sin embargo, que tras el recurso de Begum, el Tribunal de apelación ha fallado a su favor señalando que la demandante debe poder ejercer "un recurso justo y efectivo» frente a la decisión del Gobierno de arrebatarle su nacionalidad. En la decisión se señala expresamente que «Sobre los hechos concretos de este caso, la ecuanimidad y la justicia deben prevalecer sobre las preocupaciones en materia de seguridad nacional, por lo que debe permitirse el derecho de la demandante a presentar apelación» (DE MiguEL, R. «Un tribunal británico permite regresar a Londres a la «novia del ISIS», El País, 16 de julio de 2020, Disponible en [fecha de última consulta: 27 de julio de 2020] https://elpais.com/internacional/2020-07-16/un-tribunal-britanicopermite-regresar-a-londres-a-la-novia-del-isis.html 
como para aquellos que, habiéndolo sido, se encuentran cumpliendo una pena de prisión ${ }^{24}$.

De este modo, como se puede apreciar, los Estados han contado con una amplia batería de medidas para enfrentarse a la posible amenaza que representan los «combatientes terroristas extranjeros». Ahora bien, tras la derrota militar del Estado Islámico y la consiguiente pérdida de territorio por parte de la organización terrorista ${ }^{25}$, parece haber surgido durante el último año un nuevo escenario en el que, salvo contadas excepciones $^{26}$, los países europeos han optado por adoptar una política esencialmente basada en el desentendimiento de sus nacionales y la preferencia de que estos sean juzgados en Siria y en $\operatorname{Irak}^{27}$. En este sentido, esta posición quedó claramente explicitada en el caso español cuando Ana María Botella, entonces Secretaria de Estado de Seguridad, afirmó en unas recientes declaraciones que el Gobierno español no tenía ninguna intención de realizar una suerte de repatriación en bloque y que, en la medida de lo posible, la situación deseable era que, siempre que no fuesen condenados a pena de muerte, estos fueran juzgados en aquellos territorios donde se encuentran ${ }^{28}$. Esta línea de actuación, por su parte, ha generado importantes tensiones internacionales con otros países como Estados Unidos o Turquía. Si, de un lado, Donald Trump ha amenazado a los países europeos con liberar a estas personas si sus

24 Para una revisión exhaustiva y actualizada de estos programas, véase especialmente, KoEHLER, D. Understanding Deradicalization. Methods, tools and programs for countering violent extremism, op. cit.

${ }_{25}$ Especialmente a partir del año 2016, el DAESH comienza a experimentar importantes derrotas militares que se materializan en una sustancial pérdida de territorio. En este sentido, para finales del 2017, solo controlaba ya el 5\% del espacio dominado entre 2013 y 2014. En marzo de 2019, las Fuerzas Democráticas Sirias provocaron la retirada de esta organización de la ciudad de Baghuz, último núcleo urbano bajo su poder. Sobre el auge y el declive del DAESH, véase, DE LA CORTE IBÁÑEZ, L. "Un califato sin territorio ni califa. Vida y muerte de Bagdadi y sus consecuencias para el futuro del Daesh y la yihad global», op. cit., pp.1-30.

26 En este sentido, MeHRA advierte que los países europeos solo han mostrado predisposición para repatriar a los menores huérfanos que se encuentran en estos campos de detención situados al norte de Siria, Para un mayor detalle sobre algunos casos, véase, MEHRA, T. «European countries are being challenged in court to repatriate their foreing fighters and families», op. cit.

27 Renard. T. y Coolsaet, R. «Losing Control Over Returnees?», Lawfare, Foreing Policy Essay, Disponible en [fecha de última consulta: 21 de mayo de 2020] https://www. lawfareblog.com/losing-control-over-returnees

28 A pesar de que Borrell señaló que los combatientes terroristas extranjeros iban a ser repatriados y sometidos, en los casos que procediese, a un proceso penal en España, pocas semanas más tarde la Secretaria de Estado de Seguridad afirmó que la posición de España era la expresada más arriba en el cuerpo de texto (CARO, L. «El Gobierno se resiste a repatriar a los españoles yihadistas en Siria para que se les juzgue allí», ABC España, 25 de octubre de 2019, Disponible en [fecha de última consulta: 21 de mayo de 2020], https://www.abc.es/espana/abci-gobierno-resiste-repatriar-espanoles-yihadistas-siria-para-juzgue-alli-201910242217_noticia.html) 
respectivos países no se hacían cargo $^{29}$, el Ministro de Interior turco, Süleyman Soylu, afirmó que Turquía no es un hotel para combatientes terroristas europeos ${ }^{30}$.

En este contexto, aunque las cifras son muy confusas, la situación actual remite a un panorama muy complejo en el que, según advierten Coolsaet y Renard, el número de "combatientes terroristas» europeos que se encuentran en campos de detención controlados por las Fuerzas Democráticas Sirias se sitúa alrededor de 430 personas, siendo la gran mayoría mujeres. Además, también se encontrarían en estos campos al menos 700 menores europeos ${ }^{31}$. Al margen de las pésimas condiciones de vida en las que tales personas sobreviven ${ }^{32}$, conviene advertir que, considerando la línea de actuación que han tomado los países europeos, su futuro no resulta especialmente prometedor puesto que, si son juzgados en países como Siria o Irak, se enfrentan a un sistema jurídico en el que no solo existe una acusada falta de transparencia e importantes limitaciones en el acceso a la defensa sino también a un modelo penal donde prácticas como la tortura y la pena de muerte son probables ${ }^{33}$. Esta situación, por su parte, da lugar a una paradoja llamativa: si, de un lado, queda claro que, para salvaguardar los derechos humanos de estas personas, los Estados europeos deberían asumir su responsabilidad y repatriarlas activamente, esta posición política, del otro lado, implicaría promover que muchas de ellas sean juzgadas conforme a una legislación antiterrorista que, al ser considerada como la máxima expresión del denominado «Derecho Penal del Enemigo ${ }^{34}$, también ha sido duramente criticada por un sector muy

29 En este sentido, Donald Trump ha llegado incluso a sugerir la posibilidad de liberar a los «combatientes terroristas extranjeros» en las fronteras europeas (EUROPA PRESS. «Trump amenaza con liberar a los miembros europeos de Estado Islámico si no son repatriados», Europa Press, 21 de agosto de 2019, Disponible en [fecha de consulta: 21 de mayo de 2020] https://www.europapress.es/internacional/noticia-trump-amenaza-liberarmiembros-europeos-estado-islamico-si-no-son-repatriados-20190821233330.htm)

30 GaLl, C. "Turkey Vows to Send ISIS Militants Home», The New York Times, 8 de noviembre de 2019, Disponible en: [fecha de última consulta: 21 de mayo de 2020] https:// www.nytimes.com/2019/11/08/world/middleeast/turkey-syria-isis-prisoners.html

31 Según advierten los autores, estos datos serían estimaciones a la baja (COOLSAET, R. y RENARD, T. «New Figures on European Nationals Detained in Syria and Iraq», Egmont Royal Institute for International Relations, 2019, Disponible en [fecha de última consulta: 21 de mayo de 2020] http://www.egmontinstitute.be/new-figures-on-european-nationalsdetained-in-syria-and-iraq/)

32 Cumming-Bruce, N. «Horrid Conditions in Syria Camp Where ISIS Families Fled Risk Fostering Extremism», The New York Times, 11 de septiembre de 2019. Disponible en [fecha de consulta: 21 de mayo de 2019] https://www.nytimes.com/2019/09/11/world/ middleeast/syria-camp-isis-families-islamic-state-extremism.html

33 Mehra, T. y Paulussen, C. "The Repatriation of Foreing Fighters and Their Families: Options, Obligations, Morality and Long-Term Thinking», International Centre for Counter-Terrorism - The Hague, Disponible en [fecha de última consulta: 21 de mayo de 2020] https://icct.nl/publication/the-repatriation-of-foreign-fighters-and-their-familiesoptions-obligations-morality-and-long-term-thinking/

34 Jakobs, G. y Cancio Melía, M. Derecho Penal del Enemigo, Madrid, Civitas, 2006. 
relevante de la doctrina jurídico penal al advertir que lesiona tales dere$\operatorname{chos}^{35}$. De este modo, lo que se abre ahora es una encrucijada en la que las opciones posibles pasan por permanecer en este desentendimiento generalizado -lo que, por su parte, implicaría la constitución de una suerte de no-derecho- o reclamar la aplicación de una normativa penal que, debido a su excepcionalidad permanente y su naturaleza expansiva, también se constituye como una base para la vulneración de derechos.

El núcleo fundamental de este artículo, precisamente, orbita en torno a esta cuestión, teniendo como objeto principal articular una reflexión crítica y propositiva sobre la situación actual de los combatientes terroristas europeos. Para ello, en primer lugar, se abordan los principales problemas que plantea la figura del retornado y que, de un modo u otro, explican la posición de cautela y rechazo que han adoptado los países europeos frente a un eventual regreso en masa de los mismos. Por otra parte, a continuación, se examina de forma específica el abanico de posibles respuestas con las que cuentan actualmente los Estados europeos para enfrentar esta problemática, argumentándose que, tanto en términos de seguridad como de protección de los derechos humanos, la repatriación activa resulta preferible frente al resto de opciones disponibles. Por último, como consecuencia de esta toma de posición y centrando específicamente su análisis en el caso español, los autores enfrentan la paradoja descrita en el párrafo inmediatamente precedente, esgrimiendo que, en la encrucijada entre el no-derecho y un derecho penal más que mejorable, siempre resulta preferible el segundo.

\section{El problema de los retornados: una aproximación a las causas que explican la posición de rechazo de los países europeos}

Como se ha podido apreciar en el apartado inmediatamente precedente, los países occidentales han tomado toda una serie de medidas para evitar que sus nacionales regresen al país tras haber viajado a una zona de conflicto con el objeto de integrarse en una organización terrorista. Esta voluntad de impedir el citado regreso, por su parte, vendría especialmente motivada por las problemáticas específicas que suscita la figura del retornado, siendo la más evidente de ellas la amenaza que re-

35 Entre otros muchos, véase, PÉREz CEPEDA, A. I., El pacto antiyihadista: criminalización de la radicalización, Salamanca, Tirant lo Blanch, 2017; LAMARCA PÉREZ, C. «Legislación antiterrorista: la normalización de la excepcionalidad», Jueces para la Democracia, núm.88, 2017, pp.39-55; PAREDES CASTAÑón, J, M. «Terrorismo y principio de intervención mínima: una propuesta de despenalización», En Alonso Rimo, A., CuERDA Arnau, M. L. Y Fernández Hernández, A. (Dir.), Terrorismo, sistema penal y derechos fundamentales (pp.63-94), Valencia, Tirant lo Blanch, 2018. 
presentan estas personas en términos de seguridad ${ }^{36}$. Ahora bien, antes de examinar detalladamente cuáles son las diferentes aristas que componen esta problemática y su alcance real, conviene advertir que no todos los «combatientes terroristas extranjeros» tienen la capacidad o intención de retornar ${ }^{37}$. En este sentido, lo primero que hay que tener en cuenta es que, según las estimaciones más recientes, al menos 1.000 «combatientes terroristas extranjeros» procedentes de la Unión Europea habrían muerto en el campo de batalla, ya sea en Siria o en Irak ${ }^{38}$. Por otra parte, también es importante considerar que la voluntad de algunas de estas personas es permanecer en la zona de conflicto o trasladarse a otras áreas donde existan conflictos emergentes ${ }^{39}$. De este modo, de la suma total de los combatientes procedentes de la Unión Europea, solo un parte de ellos tendría intención o la capacidad de retornar ${ }^{40}$. De hecho, se calcula que, para finales del año 2017, aproximadamente el 30\% de los «combatientes terroristas europeos» habría retornado a sus lugares de origen ${ }^{41}$, aunque, por motivos evidentes, esta cifra es muy difícil de precisar.

36 VIDINO, L. «European foreing fighters in Syria: dynamics and responses», op. cit., p.218. No obstante, conviene advertir que, según apunta MALET, esta preocupación de los países occidentales por la figura del retornado es en cierta parte novedosa, ya que, durante las décadas de los años ochenta y noventa, esta no estaba presente (MALET, D. «The European Experience with Foreing Fighters and Returness», en Renard, T. y Coolsaet, R. (Eds.), Returnees: Who Are They, Why Are They (Not) Coming Back and How Should We Dealt With Them, Egmont Paper, núm.101, 2018. p.14).

37 Sobre los diferentes caminos que puede seguir un "combatiente terrorista extranjero", véase, Reed, A., Van ZuiJdewiJn, R. y BAKKeR, E. "Pathways of Foreing Fighters: Policy Options and Their (Un)Intended Consequences», International Centre for Counter-Terrorism-The Hague, ICCT Policy Brief, 2015, pp.1-19. En este sentido, PoKalova advierte que, especialmente a raíz de la pérdida de territorio por parte del DAESH, algunas de estas personas se habrían trasladado a países como Afganistán, Libia o Filipinas (Pokalova, E. Returning Islamist Foreing Fighters. Threats and Challenges to the West, op. cit., p.81).

38 PoKalova, E. Returning Islamist Foreing Fighters. Threats and Challenges to the West, Switzerland, op. cit., p.81.

39 Precisamente, este fue el camino que siguió una parte significativa de los «combatientes terroristas extranjeros» que participaron en el conflicto derivado de la guerra soviético-afgana, bien permaneciendo en el territorio o trasladándose a otros lugares como Bosnia, Chechenia, Argelia o Sudan (Byman, D. y ShapIro, J. «Be Afraid. Be A Little Afraid: The Threat of Terrorism from Western Foreing Fighters in Syria and Iraq", Foreing Policy at Brookings, Policy Paper, núm,34, 2014, p.21). Según advierte BARRET, en el contexto de la oleada actual, algunos posibles destinos podrían ser países como Libia, Somalia o Uzbekistán (BARRET, R. «Beyond the Caliphate: Foreing Fighters and the Threat of Returnees», The Soufan Center, 2017, p.11).

40 Según las estimaciones realizadas por CRANING, es esperable que, una vez finalice el conflicto sirio, el $80 \%$ de los «combatientes terroristas extranjeros» retornen a sus países de origen (CRANING, K. R. «The Challenge of Foreing Fighter Returnees», Journal of Contemporary Criminal Justice, 2017, p.15).

${ }_{41}$ EuRopol. «European Union Terrorism Situation and Trend Report 2019», op. cit., p.26. Sobre esta cuestión, conviene advertir que, según el estudio realizado por el Parlamento Europeo, la gran mayoría de ellos habrían retornado antes de los atentados de París en noviembre de 2015. Asimismo, este estudio pone en evidencia que la tasa de retornados no ha sido uniforme en todos los países de la Unión Europea. Mientras que, 
Las dificultades existentes a la hora de contrastar los datos representan un hándicap en la investigación sobre los CET y su destino que merece una atención específica. La persistencia de la guerra en Siria y la compleja situación política en Irak son los factores esenciales que impiden contar con datos oficiales certeros y globales, lo que conduce a utilizar estimaciones sobre la base de fuentes indirectas, a partir de los medios de comunicación (que no siempre referencian sus fuentes) o de informes publicados por entidades privadas o grupos de investigación que en ocasiones se referencian de forma recíproca, lo que impide determinar una pluralidad efectiva de fuentes que garantice el contraste. En el Décimo informe del Secretario General sobre el EIIL (Dáesh) ${ }^{42}$ se exponen estas dificultades y se hace remisión a los Informes analíticos específicos, llevados cabo por el Comité de Lucha contra el Terrorismo del Consejo de Seguridad de UN. En estimaciones del Índice Global de Terrorismo (GTI), elaborado por The Institute for Economics \& Peace (IEP), en julio de 2019 habrían regresado el 16\% de los 52.808 combatientes yihadistas extranjeros computados en Siria. Con relación a Europa, el GTI 2019 señala que habrían regresado (hasta julio de 2019), unos 2.384, que representarían un $45 \%$ de los varones que habían viajado, pero sólo un $18 \%$ de las mujeres. A pesar de estas publicaciones, a las dificultades de evaluación más arriba referidas se añaden las derivadas de la inexistencia de información abierta y directa desde los Ministerios del Interior y la policía de los diferentes Estados: el regreso de los combatientes ya no es sólo percibido por los Gobiernos exclusivamente como un problema de seguridad, sino como un serio problema político, el de presentar ante una opinión pública notablemente influida por el discurso de la deshumanización del terrorista, la responsabilidad de la repatriación para el enjuiciamiento.

Pero, ¿cuáles son los principales problemas que plantea la figura del retornado y explican en cierto modo la posición de cautela y rechazo seguida por los países occidentales?

por ejemplo, en Reino Unido este valor se situaría en torno al 50\% del total, en Francia solo habría retornado el 12\% (EUROPEAN PARLIAMENTARY RESEARCH SERVICE. "The return of foreing fighters to EU soil. Ex-post evaluation», European Parliament, Study, pp. 31 y ss). En lo que se refiere de forma específica al caso español, se calcula que, de las más de 230 personas que se habrían trasladado a tales zonas de conflicto, el 25\% de ellos habría fallecido y casi un $20 \%$ habría retornado (GoBIERNo DE EsPAÑA. Estrategia Nacional contra el Terrorismo, op cit., p.19). Para un mayor detalle sobre las rutas seguidas por los «combatientes terroristas extranjeros» para retornar a Europa, véase, RADICALISATION AwERENESS NETWORK. "RAN Manual. Responses to Returnees: Foreing terrorist fighters and their families», RAN, 2017, p.19.

42 Décimo Informe del Secretario General de UN sobre la amenaza que plantea el EIIL (Dáesh) para la paz y la seguridad internacionales y la gama de actividades que realizan las Naciones Unidas en apoyo de los Estados Miembro para combatir la amenaza. Informes del Secretario General de Naciones Unidas al Consejo de Seguridad en 2020. Disponible en: https://www.un.org/securitycouncil/es/content/informes-del-secretario-general-al-consejo-de-seguridad-en-2020. 
En términos generales, la principal preocupación en torno a los retornados se refiere a una cuestión puramente securitaria ${ }^{43}$. En este sentido, lo que se pone en evidencia es la amenaza que supone para la seguridad nacional el hecho de permitir la entrada al país de una persona que, estando abiertamente radicalizada, cuenta con experiencia militar en un conflicto bélico, tiene conocimientos sobre el uso y el manejo de armas y, además, está relacionada internacionalmente con otros combatientes terroristas extranjeros ${ }^{44}$. De este modo, el miedo no sería otro que, una vez haya retornado, el individuo aproveche su experiencia para participar en la comisión de actos de terrorismo doméstico. Más aún, teniendo en cuenta que, desde que comenzase a perder territorio en el año 2015, el DAESH ha intensificado su campaña propagandística contra Occidente ${ }^{45}$. Por su parte, esta posibilidad, lejos de ser meramente especulativa, se habría materializado recientemente en los atentados de París en el año $2015^{46}$ y de Bruselas en $2014^{47}$ y $2016^{48}$. No obstante, conviene advertir que no todos los individuos que retornan necesariamente representan una amenaza a la seguridad ${ }^{49}$. Sobre esta cuestión, por ejemplo, Pokalova advierte que, en el caso de aquellos individuos que han regresado

43 Vidino, L. «European foreing fighters in Syria: dynamics and responses», op. cit., p. 218 .

44 Byman, D. «The homecomings: What Happens When Arab Foreing Fighters in Iraq and Syria Return», op. cit., p.2.

45 Según advierte PoKALOva, una vez que el DAESH comienza a perder territorio en el año 2015, este grupo recalibra en cierta manera sus prioridades e intensifica su campaña contra los países occidentales, no solo incitando a la comisión de atentados sino también participando en su planificación y ejecución. Para un mayor detalle, véase especialmente, Pokalova, E. Returning Islamist Foreing Fighters. Threats and Challenges to the West, op. cit., p.82.

46 El 13 de noviembre de 2015 tuvo lugar en París una sucesión de ataques terroristas coordinados que dejaron un total de 129 fallecidos. De los 30 individuos que participaron en el ataque, 16 de ellos habían sido «combatientes terroristas extranjeros» en Siria e Irak. Para un mayor detalle, véase, CRAGIN, K. R. "The November 2015 Paris Attacks: The impact of Foreing Figther Returnees», Orbis, Spring, 2017, pp.1-15.

47 El 24 de mayo de 2014, Mehdi Nemmouche atacó el Museo Judío de Bruselas, matando a cuatro personas. La investigación policial reveló que, en el año 2013, este había viajado a Siria para integrarse en el DAESH, donde permaneció durante un periodo de un año (BBC. «Brussels Jewish Museum: Mehdi Nemmouched jailed for life», BBC, 12 de marzo de 2019, Disponible en [fecha de consulta: 26 de mayo de 2020] https://www. bbc.com/news/world-europe-47533533).

48 El 22 de marzo de 2016 tuvo lugar en Bruselas un doble ataque terrorista en el aeropuerto de Bruselas y la estación de metro de Maalbeek que causó 32 fallecidos y más de 340 heridos. En este sentido, la gran mayoría de los integrantes de la célula terroristas habían viajado previamente a Siria para integrarse en el DAESH (COOLSAET, T. Y RENARD, T. "How Belgium Overcame the Threat from Returing Foreing Terrorist Fighters», Egmont Royal Institute for International Relations, Comentarios, 22 de marzo de 2018, Disponible en [fecha de última consuta: 27 de mayo de 2020] http://www.egmontinstitute.be/howbelgium-overcame-the-threat-from-returning-foreign-terrorist-fighters/).

49 De hecho, según advierten BYMAN Y SHAPIRO, esta amenaza suele ser fácilmente exagerada (BYMAN, D. Y SHAPIRO, J. «Be Afraid. Be A Little Afraid: The Threat of Terrorism from Western Foreing Fighters in Syria and Iraq», op. cit., p.1). 
especialmente desilusionados y desmotivados, ya sea por cuestiones referidas al liderazgo, la naturaleza de las tácticas insurgentes llevadas a cabo o por el simple hecho de no estar preparados ni física ni psicológicamente para ser combatientes terroristas extranjeros, es más probable que, en lugar de cometer actos de terrorismo doméstico, la persona llegue incluso a cooperar con las agencias de seguridad ${ }^{50}$.

Desde la literatura especializada, en estos términos, se ha examinado de forma empírica si realmente los «combatientes terroristas extranjeros» representan una amenaza para sus lugares de origen una vez retornan a los mismos, con resultados no siempre coincidentes. En este sentido, según la investigación efectuada por Hegghammer, de los individuos que retornaron entre 1980 y 2010 después de participar en estos conflictos, el 11\% de ellos participó en actos de terrorismo doméstico en Occidente. Asimismo, según advierte este autor, los ataques en los que participaron tendieron a ser más exitosos y letales ${ }^{51}$. En un estudio más reciente, Hegghammer y Nesser han analizado el rol desempeñado por los «combatientes terroristas extranjeros» en los atentados cometidos en Occidente durante el periodo comprendido entre enero de 2011 y junio de 2015, llegando a la conclusión de que, de los 69 ataques -tanto consumados como frustrados- que componen su base de datos, 16 de ellos involucraron la participación de al menos un «combatiente terrorista extranjero» ${ }^{52}$. En una línea similar, Bakker y sus colaboradores han señalado que, de todos los yihadistas que fueron condenados en Europa por actividades relacionadas con el terrorismo entre 2001 y 2009, el 13\% de ellos había estado en el extranjero de forma previa al ataque, ya sea para recibir entrenamiento o participar en un conflicto ${ }^{53}$.

Holman, sin embargo, ha llegado a una conclusión diferente en su estudio, advirtiendo que, en el caso de los «combatientes terroristas extranjeros» procedentes de Francia y Bélgica que se trasladaron a Irak a partir del año 2003, estos no han participado especialmente ni en la planificación ni en la ejecución de actos de terrorismo doméstico cuan-

50 PoKalova, E. Returning Islamist Foreing Fighters. Threats and Challenges to the West, op. cit., p.82.

51 Sin embargo, conviene advertir que, según apunta el autor, este $11 \%$ debe ser entendido con cautela ya no todos los retornados han sido cuantificados en su base de datos (Hegghammer, T. "Should I Stay or Should I Go? Explaining Variation in Western Jihadist' Choice between Domestic and Foreing Fighting», American Political Science Review, vol.107, núm.1, 2013, pp.1-15).

52 De estos 16 ataques, 9 de ellos implicaron a un total de 11 personas que se habían trasladado a Siria previamente, de los cuales 6 habrían sido entrenados por el DAESH (Hegghammer, T. y Nesser, P. "Assessing the Islamic State's Commitment to Attacking the West», Perspectives on Terrorism, vol.9, núm.4, 2015, p.20).

53 Bakker, E., Paulussen, C. y Entenmann, E. «Returning Jihadist Foreing Fighters. Challenges Pertaining to Threat Assessment and Governance of this Pan-European Problem», Security and Human Rights, núm.25, 2015, p.17. 
do han retornado a sus países de origen ${ }^{54}$. Por otra parte, en referencia específica al caso británico, Qureshi ha señalado que, de las 66 personas que se han visto involucradas en actos de terrorismo doméstico desde el año 2001 hasta 2014, solo dos de ellos habían luchado en el extranjero ${ }^{55}$. Más recientemente, Renard ha afirmado que, si se compara con el número total de retornados, la participación de estas personas en actos de terrorismo doméstico es muy baja ${ }^{56}$. Asimismo, Malet y Hayes sostienen que, en el caso de que estas personas participen en este tipo de actos, la gran mayoría de ellas lo hace inmediatamente después de retornar, lo que supondría que esta sea sobre todo una amenaza a corto plazo ${ }^{57}$.

Ahora bien, como advierte Pokalova, de la misma manera que muchos de estos autores en sus propios artículos, resulta muy complicado medir cuál es el riesgo real que tienen los «combatientes terroristas extranjeros» de participar en actos de terrorismo doméstico ya que, además de la marcada ausencia de información que existe en algunos casos, no todos los retornados son detectados por las autoridades a su regreso, lo que impide establecer una proporción fehaciente entre los que participan en actos de terrorismo y los que $\mathrm{no}^{58}$. En todo caso, las investigaciones existentes parecen sugerir claramente que, si bien es cierto que los retornados representan una amenaza a la seguridad, también lo es que esta no debe ser exagerada ${ }^{59}$. Asimismo, otro aspecto que también ha sido destacado desde el punto de vista securitario es la posibilidad de que los retornados ejerzan labores de captación y reclutamiento, sobre todo teniendo en cuenta el estatus que se deriva de su participación previa en un conflicto bélico ${ }^{60}$. En este sentido, Cillufo y sus colaboradores esgrimen que estos pueden llegar a ser contemplados como una suerte de

54 Holman, T. «Belgian and French Foreing Fighters in Iraq 2003-2005: A Comparative Case Study», Studies in Conflict and Terrorism, 2015, pp.1-19.

55 QuReshI, A. Blowback - Foreign Fighters and the Threat They Pose. Londres: Cage, 2014, p.12.

56 RENARD, T. "How to handle returning foreing fighters: policies and challenges», European Parliament, 2018.

57 Según afirman los autores, de los combatientes terroristas extranjeros que llegan a involucrare o intentan llevar a cabo actos de terrorismo doméstico en Occidente, la gran mayoría de ellos lo hacen en el transcurso de un año desde su llegada. Una vez pasado este tiempo, el riesgo se reduciría considerablemente (MALET, D. y HAYES, R. «Foreing Fighter Returnees: An Indefinite Threat?» Terrorism and Political Violence, 2018, p.15)

58 PoKalova, E. Returning Islamist Foreing Fighters. Threats and Challenges to the West, op. cit., p.60.

59 Byman, D. y ShapIRo, J. «Be Afraid. Be A Little Afraid: The Threat of Terrorism from Western Foreing Fighters in Syria and Iraq», op. cit., p.1.

60 BYMAN, D. «The homecomings: What Happens When Arab Foreing Fighters in Iraq and Syria Return», op. cit., p.6. Esta posibilidad, según señala PoKALOvA, se materializó de una forma especialmente intensa tras la finalización del conflicto afgano-soviético. Al no poder regresar a sus países de origen, algunos de estos combatientes se dirigieron a países europeos -especialmente Reino Unido-, donde se dedicaron a diseminar una versión radical y belicosa del Islam y a reclutar nuevos miembros. En este sentido, el Londres de los años noventa llegó a ser conocido por las agencias de seguridad como Londonistan 
rockstars con gran capacidad de influencia sobre determinados grupos de riesgo ${ }^{61}$. Además, también existe constancia de que, tras regresar, algunas de estas personas habrían contribuido a facilitar el viaje de otros a estas zonas de conflicto, contribuyendo de este modo a retroalimentar la potencialidad de la amenaza ${ }^{62}$.

Por otra parte, al margen de esta dimensión securitaria, otra problemática que ha suscitado la figura del retornado se refiere a una cuestión puramente legal. En este sentido, los países occidentales han puesto de relevancia la dificultad existente para juzgar a estas personas, sobre todo en lo que se refiere a la recolección de evidencias que sirvan para probar su participación en una organización terrorista o la comisión de actos de terrorismo ${ }^{63}$. Más aun, teniendo en cuenta la situación actual en la que se encuentran Siria e Irak ${ }^{64}$. En este sentido, es importante considerar que no todas las personas que se han desplazado a estos territorios lo han hecho por motivos relacionados con el terrorismo ${ }^{65}$. Por ello, para poder discernir entre unos casos y otros, algunos países han optado por emplear informes emitidos por diferentes organizaciones no gubernamentales que actúan sobre el terreno o, directamente, documentos disponibles en redes sociales como Facebook, Twitter o Youtube, lo que no

(Pokalova, E. Returning Islamist Foreing Fighters. Threats and Challenges to the West, op. cit., p.62).

${ }_{61}$ Cillufo, F. J., Cozzens, J. B. y Ranstorp, M. «Foreing Fighters. Trends, Trajectories \& Conflict Zones», Homeland Security Police Institute, 2010, p.24.

62 Sobre esta cuestión, véase por ejemplo, el caso de Lahcen Ikassrien: ALtozano, M. "11 años y medio de cárcel a un expreso de Guantánamo por mandar voluntarios a Siria», El Confidencial, 28 de septiembre de 2016. Disponible en [fecha de última consulta: 28 de mayo de 2020 https://www.elconfidencial.com/espana/2016-09-28/11-anos-y-medio-decarcel-a-un-expreso-de-guantanamo-por-mandar-voluntarios-a-siria_1267271/.

63 MARRERo Rocha, I. «Los combatientes «terroristas» extranjeros de la Unión Europea a la luz de la Resolución 2178 (2014) del Consejo de Seguridad de Naciones Unidas», op. cit., p.583.

64 Para paliar esta problemática, se ha puesto en marcha la denominada Operación Gallant Phoenix en la que colaboran diferencias agencias de inteligencia y seguridad occidentales con el objetivo de recoger evidencias sobre el terreno (LóPEZ-FonsECA, O. «Agentes españoles colaboran en Siria en una operación de EEUU para identificar yihadistas europeos», El País, 4 de marzo de 2019, Disponible en [fecha de última consulta: 29 de mayo de 2020] https://elpais.com/politica/2019/03/03/actualidad/1551607296_074638. html).

65 Según advierte MARRERo Rocha, algunas personas se habrían desplazado a Siria o Irak para colaborar, por ejemplo, con organizaciones no gubernamentales musulmanas que trabajan sobre el terreno (MARRERO ROCHA, I. «Los combatientes «terroristas» extranjeros de la Unión Europea a la luz de la Resolución 2178 (2014) del Consejo de Seguridad de Naciones Unidas», op cit. Aquí también ha surgido la problemática de cómo enfrentar aquellos casos en los que existe un traslado a Siria e Irak pero no para integrarse en el DAESh, sino para combatir contra ellos. En este sentido, véase, Paulussen, C. y PITCHER, K. «Prosecuting (Potential) Foreing Fighter: Legislative and Practical Challenge», International Centre for Counter-Terrorism- The Hague, ICCT Research Paper, 2018, pp.2325 . 
siempre ha sido aceptado como documentos probatorios válidos ${ }^{66}$. Todo ello, por su parte, ha generado cierta dificultad para llegar a sentencias condenatorias. Por ejemplo, en el caso de Reino Unido, únicamente han sido perseguidos penalmente 1 de cada 10 retornados, lo que necesariamente implica que el resto se encontraría en una situación de libertad ${ }^{67}$.

Asimismo, cuando se llega a sentencias condenatorias que implican la imposición de una pena de prisión, otra cuestión que ha sido frecuentemente señalada es que los retornados podrían aprovechar su estancia en el centro penitenciario para radicalizar a otros internos, de modo que, una vez terminen su condena, estos últimos puedan pasar a engrosar las filas de la organización y, eventualmente, participar en la planificación y comisión de actos de terrorismo ${ }^{68}$. En este sentido, conviene advertir que, desde la literatura especializada, las prisiones han sido generalmente visualizadas como espacios aptos para la radicalización yihadista ${ }^{69}$. Al

66 Menra, T. «Bringing (Foreing) Terrorist Fighters to Justice in a Post-Isis Landscape Part III: Collecting Evidence from Conflict Situations", International Centre for CounterTerrorism- The Hague, 12 de junio de 2018, Disponible en [fecha de última consulta: 28 de mayo de 2020].

67 DEARDEN, L. "Only one in 10 jihadis returning from Syria prosecuted, figures reveal», Independent, 21 de febrero de 2019, Disponible en [fecha de última consulta: 10 de junio de 2020] https://www.independent.co.uk/news/uk/home-news/shamima-begumisis-return-uk-syria-jihadis-terror-threat-prosecute-nationality-a8790991.html. En lo que se refiere de forma específica al caso español, de las aproximadamente 50 personas que han retornado, 20 de ellas se encontrarían en prisión, ya sea en España o en Marruecos (REINARES, F. «Yihadistas retornados tras desplazarse de España a Siria e Irak: ¿qué motivos tienen?, ¿dónde están ahora?, ¿suponen un peligro», op. cit., p.2).

68 Pokalova, E. Returning Islamist Foreing Fighters. Threats and Challenges to the West, op. cit., p.144.

69 Sobre esta cuestión, véase, entre otros muchos, CuthBertson, I. M. «Prisons and the Education of Terrorist», World Policy Journal, 3, 2004, pp.15-22; CiLlufo, F. y SAAтноғ, G. "Out of the Shadows. Getting ahead of prisoner radicalization», The George Washington Homeland Security Policy Institute, Special Report, 2006, pp.1-38; SILKE, A. "Terrorist, extremist and prison: an introduction to the critical issues», en (SILKE, A. ed.), Prisons, Terrorism and Extremism. Critical Issues in Management, Radicalisation and Reform, Routledge, Londres, 2014; AwAN, I. "Muslim Prisoners, Radicalization and Rehabilitation in British Prisons", Journal of Muslim Minority Affairs, 3, 2013, pp.371384; Rushchenko, J. "Terrorist recruitment and prison radicalization: Assessing the UK experiment of separation centres», European Journal of Criminology, Special Issue: Understanding European Jihadist: criminal, extremist or both, 2019, pp.1-20; NISTAL Burón, J. «Radicalización en prisión», en (Bermejo Casado, R. y Bazaga Fernández, I. eds.) Radicalización violenta en España. Detección, gestión y respuesta (pp.121-131), Tirant lo Blanch, Valencia, 2019. Ahora bien, el hecho de que sean «espacios aptos para la radicalización yihadista» no implica que sean los espacios de radicalización por excelencia. Por ejemplo, en el caso español, REINAREs y sus colaboradores han puesto en evidencia que, de los yihadistas condenados o muertos en España desde 1996 hasta octubre del 2018, el 10,5\% abrazó los postulados del islam radical mientras se encontraba en prisión. En este sentido, los autores constatan que los domicilios privados, los lugares de culto y los espacios al aire libre arrojaron porcentajes superiores. Para un mayor detalle, véase, Reinares, F., García-Calvo, C. y Vicente, A. Yihadismo y yihadistas en España. Quince años después del 11-M, Real Instituto Elcano, Madrid, 2019, p.67. SILKE y VeldHUIS, en 
fin y al cabo, según indica Neumann, estas no harían sino constituirse como «espacios de vulnerabilidad» en los que las personas tienden a experimentar crisis existenciales que, unidas al aislamiento social que conlleva esta pena, incrementan su vulnerabilidad ante la recepción de mensajes extremistas ${ }^{70}$. Como prueba empírica de este fenómeno, por su parte, han sido citados toda una serie de ejemplos paradigmáticos que abarcan desde el caso de importantes miembros del Estado Islámico en las cárceles iraquíes ${ }^{71}$ a otras figuras como Richard Reid ${ }^{72}$ o Jamal Ahmidan ${ }^{73}$. En este contexto, la entrada en prisión de los retornados ha sido presentada como una medida que, si bien es cierto que en el corto plazo podría resultar efectiva al neutralizar de forma inmediata la posible peligrosidad de estas personas, también lo es que, pensando en el largo plazo y atendiendo a las dinámicas descritas en este párrafo, podría resultar incluso contraproducente ${ }^{74}$. Además, en aquellos casos en los que no existan programas de tratamiento efectivos en prisión para propiciar

una línea similar, han señalado que la radicalización yihadista en prisiones no deja de resultar un fenómeno anecdótico (SILKE, A. y Veldhuis, T. «Countering Violent Extremism in Prisons: a review of key recent research and critical research gaps», Perspectives on Terrorism, 5, 2017, p.3.).

70 Neumann, P. «Prison and Terrorism. Radicalisation and Deradicalisation in 15 countries», The International Centre for the Study of Radicalisation and Political Violence, 2010, p.3.

${ }_{71}$ Las cárceles de Irak han sido presentadas como el ejemplo paradigmático de este fenómeno. Tras la disolución de las fuerzas armadas locales y la adopción de una política especialmente represiva, el número de personas encarceladas en este país experimentó un súbito crecimiento a raíz de la intervención estadounidense en el año 2003, propiciando que, en el mismo espacio, confluyeran líderes carismáticos, militares y diversos tipos de delincuentes. Como consecuencia, en los centros de detención -especialmente Camp Bucca- se tejieron toda una serie de relaciones que, finalmente, terminarían por cimentar las bases para el desarrollo de importantes organizaciones terroristas. En este contexto, RUSHCHENKo advierte que una parte significativa de la cúpula del Estado Islámico estaría compuesta por miembros que han pasado en algún momento de sus vidas por estas prisiones. Para un mayor detalle, véase, RushchenKo, J. «Terrorist recruitment and prison radicalization: Assessing the UK experiment of separation centres», op. cit., p.2 e IGUALADA Tolosa, C. «La radicalización yihadista en el entorno de las prisiones», Instituto Español de Estudios Estratégicos, Documento de Opinión, 2017, pp. 3-7.

72 Más conocido como the shoe bomber -el terrorista del zapato-, Reid se convirtió al Islam en un centro de menores británico mientras cumplía una pena por una serie de atracos, participando posteriormente en un intento de atentado que consistió en tratar de explotar una bomba en un avión que cubría la ruta entre París y Miami. Sobre el proceso de radicalización acometido por Reid, véase, JAGER, A. «The «shoe bomber» Richard Reid. His radicalization explained», International Institute for Counter-Terrorism, 2018, pp.1-14.

73 Jamal Ahmidan, considerado como una de las figuras más relevantes en la gestación de los atentados del 11 de marzo de Madrid, se adhirió a una corriente radical del Islam cuando se encontraba preso por un delito común en un cárcel marroquí. Véase, GutiéRrez, J. A., Jordán, J. y Trujillo, H. «Prevención de la radicalización yihadista en las prisiones españolas. Situación actual, retos y disfunciones del sistema penitenciario español», Athena Intelligence Journal, 1, 2008, p. 4.

74 Pokalova, E. Returning Islamist Foreing Fighters. Threats and Challenges to the West, op.cit., p.8. 
la desvinculación o desradicalización ${ }^{75}$ de los retornados, su paso por prisión podría contribuir a consolidar e incluso potenciar el proceso de radicalización acometido ${ }^{76}$. Sobre esta cuestión, el caso español resulta paradigmático ya que, si bien es cierto que la Instrucción 2/2016 de la Secretaria General de Instituciones Penitenciarias introduce un programa de intervención específico con sujetos ya radicalizados, su carácter esencialmente securitario termina por desplazar la búsqueda de la rehabilitación y la reinserción social a una posición totalmente marginal ${ }^{77}$.

Por último, cabe mencionar al menos dos problemas más que plantea la figura del retornado: de un lado, es importante advertir que, tal y como ha puesto en evidencia un sector muy amplio de la doctrina penal y criminológica ${ }^{78}$, la Política Criminal Contemporánea se encuentra fuertemente politizada y mediatizada, de modo que, en detrimento de los expertos, la voz de la opinión pública se convierte cada vez más en un factor decisivo a la hora de tomar decisiones relativas al fenómeno delictivo y su tratamiento. En este sentido, debido a las problemáticas expuestas más arriba, sobre todo en lo que se refiere a la posible amenaza a la seguridad que representan los retornados, parece evidente que la opinión pública no se va a mostrar especialmente partidaria de promover o facilitar el regreso de los «combatientes terroristas extranjeros»y menos aún de que lo hagan sin pasar una larga temporada en prisión ${ }^{79}$. En una reciente consulta realizada en Francia, por ejemplo, el 82\% de la muestra encuestada afirmó preferir que los adultos permaneciesen en Siria o Irak ${ }^{80}$. Esto, por su parte, dificultaría enormemente la pre-

75 Mientras que, de un lado, la desvinculación se referiría esencialmente a un aspecto conductual -es decir, su objetivo no sería otro que el hecho de que la persona abandone la organización o grupo terrorista-, la desradicalización también buscaría incidir en aspectos cognitivos. Para un mayor detalle sobre esta diferenciación, véase especialmente, HoRGAN, J. «Deradicalization or Disengagment? A process in need of clarity and a Counterterrorism initiative in need of evaluation», Perspectives on Terrorism, vol.2, núm.4, 2008, pp.1-5.

${ }_{76}$ Este hecho, por ejemplo, ha sido observado por ACALE en su análisis sobre el caso español a partir del estudio de la Introducción SGIP 2/2016, denominada como «Programa Marco de intervención en radicalización violenta con internos islamistas». Para un mayor detalle, véase, (AcAlE SÁNchez, M. «Terrorismo y tratamiento punitivista: más allá de la prisión», en (Pérez Cepeda, A. I., Dir.) El terrorismo en la actualidad: un nuevo enfoque político criminal, Tirant lo Blanch, Valencia, 2018).

77 Para un mayor detalle, véase, Fernández ABAD, C. «La doble problemática del terrorismo yihadista en prisión: una aproximación crítica a la respuesta del sistema penitenciario español», Indret. Revista para el análisis del Derecho, 3, 2020, p. 331.

78 Díez Ripollés, J. L. «El nuevo modelo penal de la seguridad ciudadana». Revista Electrónica de Ciencia Penal y Criminología, 6(03), 2004, pp.1-34; GARLAND, D. La cultura del control. Crimen y Orden Social en la sociedad contemporánea. Barcelona, Gedisa, 2005; Del Rosal Blasco, B. "¿Hacía un Derecho penal de la postmodernidad?», Revista Electrónica de Ciencia Penal y Criminología, 11(08), 2009, pp.1-64.

79 Dworkin, A. «Beyond Good and Evil: Why Europe Should bring ISIS Foreing Fighters Home», European Council on Foreing Relations, Policy Brief, Octubre 2019, p.7.

80 Cebrián, P. «¿Horca o cárcel iraquí? El incierto destino de los 57 yihadistas españoles detenidos en Siria», El Confidencial, 2 de agosto de 2019, Disponible en [fecha de 
tensión de cualquier gobierno que quiera ir en una línea diferente a esta dirección ${ }^{81}$. De otro lado, una cuestión que también ha preocupado a los países europeos se refiere a las posibilidades de reintegración que tienen estas personas después de haber participado en un conflicto bélico o, en una dimensión más general, ser ciudadanos del autodenominado Estado Islámico ${ }^{82}$. En estos términos, aunque es cierto que existen numerosos programas orientados tanto a la desvinculación de estas personas con respecto a las organizaciones de las que forman parte como a su desradicalización, también lo es que, al menos por el momento, se desconoce la eficacia de los mismos ya que estos raramente han sido evaluados ${ }^{83}$.

Todas estas diferentes problemáticas explican, de un modo u otro, la posición de cautela y rechazo que, en términos generales, han mantenido los países europeos frente a un hipotético regreso en masa de los «combatientes terroristas extranjeros", lo que ha desembocado en la reciente adopción de una política conjunta que esencialmente estaría basada en el desentendimiento de sus nacionales y la preferencia de que estos sean juzgados en Siria o Irak. Ahora bien, ¿es esta la única respuesta posible para enfrentar el fenómeno abordado a lo largo de este apartado?

\section{Tres tipos de respuestas posibles: un alegato en favor de la repatriación activa de los «combatientes terroristas extranjeros»}

Los Estados europeos han barajado al menos tres alternativas diferentes para responder ante el fenómeno de los «combatientes terroristas extranjeros» una vez que se ha producido la derrota militar sobre el DAESH y este ha perdido la totalidad del territorio que controlaba en Siria e Irak. Por una parte, la primera opción posible pasaría por no hacer nada en particular y dejar que los ciudadanos europeos sean perseguidos por las autoridades locales, ya sean sirias o iraquíes ${ }^{84}$. En este sentido,

última consulta: 1 de junio de 2020] https://www.elconfidencial.com/mundo/2019-08-02/ destino-yihadistas-espanoles-detenidos-siria_2158327/

81 Bakker, E., Paulussen, C. y Entenmann, E. «Returning Jihadist Foreing Fighters. Challenges Pertaining to Threat Assessment and Governance of this Pan-European Problem», Security and Human Rights, núm.25 p.30.

82 Hoffman, A. y Furlan, M. "Challenges posed by returning foreing fighters", Program on Extremist. The George Washington University, 2020, p.15.

83 Sobre esta cuestión, véase especialmente, HORGAN, J. y BRADDOCK, K. «Rehabilitating the Terrorist? Challenges in Assessing the Effectiveness of Deradicalization Programs», Terrorism and Political Violence, 22:2, pp.267-291 y KoEHLER, D. Understanding Deradicalization. Methods, tools and programs for countering violent extremism, New York, Routledge, 2017, p.164 y ss.

84 La opción de que los «combatientes terroristas extranjeros» procedentes de Europa sean juzgados por los kurdos ha sido mayoritariamente descartada debido a que estos no son reconocidos internacionalmente como un Estado. Además, también existen series 
se ha argumentado que, al irse voluntariamente a participar en un conflicto bélico, ahora estas personas deben enfrentar las consecuencias que se deriven de sus acciones previas ${ }^{85}$. Además, también se ha señalado la preferencia de que, de acuerdo al principio de territorialidad, los hechos sean juzgados en el lugar donde se cometió el delito ${ }^{86}$. Tal y como se ha sostenido más arriba, esta habría sido la opción que han asumido la inmensa mayoría de los países europeos ${ }^{87}$, pasando de las palabras a los hechos. En estos términos, recientemente, Irak condenó por primera vez a tres ciudadanos franceses a la pena de muerte por unirse al Estado Islámico $^{88}$.

Ahora bien, esta línea de actuación plantea al menos tres grandes problemas: de un lado, es muy probable que, a pesar de que se insista en lo contrario ${ }^{89}$, estas personas no vayan a ser sometidas a un procedimiento penal con todas las garantías, existiendo una probabilidad muy alta de que, además de ser torturados, sean condenados a cadena perpe-

dudas de que cuenten con la capacidad logística para ello (MEHRA, T. y PAulussEn, C. «The Repatriation of Foreing Fighters and Their Families: Options, Obligations, Morality and Long-Term Thinking», op. cit.

85 Sobre esta cuestión, por ejemplo, el Ministro de Exteriores Francés, Jean-Yves Le Drian, afirmó recientemente que los ciudadanos franceses deben ser considerados como enemigos de Francia y juzgados en Siria e Irak por los crímenes que han cometido (REUTERS. "France snubs Trump's appeal to repatriate IS fighters en masse, for now», Reuters, 18 de febrero de 2019, Disponible en [fecha de última consulta: 10 de junio de 2020] https:/www.reuters.com/article/us-mideast-crisis-syria-france/france-snubstrumps-appeal-to-repatriate-is-fighters-en-masse-for-now-idUSKCN1Q70KV.

86 Precisamente, en estos términos, se pronunció recientemente el Presidente de Irak, Barham Salih, al afirmar que «aquellos que estén implicados en crímenes contra Irak y contra las instalaciones y personal iraquí, los buscaremos para juzgarlos en tribunales iraquíes» (AFP. "Irak juzgará a 13 franceses del Estado Islámico», La Vanguardia, Disponible en [fecha de consulta: 5 de junio de 2020' https://www.lavanguardia.com/ internacional/20190226/46696142821/irak-juzgara-franceses-estado-islamico.html). En un sentido similar, el Ministro de Exteriores de Bélgica afirmó que la posición del país era que estas personas fuesen juzgadas lo más cerca posible del lugar donde cometieron los delitos (EURONEWS. "Belgian and UK authorities say ISIS fighters should face justice in Iraq and Syria», Euronews, 3 de noviembre de 2019, Disponible en [fecha de última consulta: 10 de junio de 2020] https:/www.euronews.com/2019/11/02/turkey-will-send-itsjihadist-prisoners-home-amid-anger-with-europe.

87 Renard. T. y CoOlsaet, R. "Losing Control Over Returnees?», op. cit.

88 AFP. "Irak condena a muerte a tres franceses por unirse al Estado Islámico», El Mundo, 26 de mayo de 2019, Disponible en [fecha de última consulta: 4 de mayo de 2020] https:/www.elmundo.es/internacional/2019/05/26/5ceab86dfc6c83896c8b468e.html.

89 En este sentido, diferentes mandatarios europeos han insistido en que esta opción es solo válida si los ciudadanos europeos son sometidos a un juicio justo y que no implique la imposición de penas que atenten abiertamente contra los derechos humanos. Por ejemplo, esta ha sido la posición asumida por el Gobierno español al afirmar que esta es una opción válida siempre y cuando los ciudadanos españoles no sean condenados a pena de muerte (CARO, L. «El Gobierno se resiste a repatriar a los españoles yihadistas en Siria para que se les juzgue allí», op. cit.). 
tua o pena de muerte ${ }^{90}$, lo que difícilmente encaja con los estándares europeos de justicia y protección de los derechos humanos. En este sentido, baste con señalar que, según Amnistía Internacional, Irak fue el cuarto país del mundo en ejecutar penas de muerte durante el año $2017^{91}$. En el caso de Siria, la situación no es muy diferente si se toma en consideración que el gobierno de Bachar el Assad ha sido acusado reiteradamente de cometer graves violaciones de los derechos humanos y que, de nuevo conforme a Amnistía Internacional, algunas prisiones sirias se constituyen como verdaderos «mataderos humanos» ${ }^{92}$. Además, también cabe señalar que, en el ranking elaborado anualmente por Transparencia Internacional, Siria e Irak se encuentran entre los cincuenta países más corruptos del mundo ${ }^{93}$. Por otra parte, es importante advertir que la situación geopolítica actual dificulta enormemente esta tarea ya que, desde que comenzó la ofensiva turca sobre las fuerzas kurdas en el norte de Siria, estos últimos tienen cada vez un menor control sobre los campos de detención en los que se encuentran los «combatientes terroristas extranjeros» procedentes de Europa, existiendo constancia de que algunos de ellos han sido liberados o, directamente, han escapado ${ }^{94}$. Por último, el hecho de presuponer que todas estas personas se han trasladado libremente a Siria e Irak también resulta altamente problemático puesto que, tal y como se señaló más arriba, uno de los rasgos distintivos de esta

90 Mehra, T. y Paulussen, C. «The Repatriation of Foreing Fighters and Their Families: Options, Obligations, Morality and Long-Term Thinking», op. cit. Por ejemplo, en uno de los juicios ya realizados contra siete ciudadanos franceses que han sido condenados a pena de muerte en la horca, no se presentó ni una sola evidencia que probase la comisión de delitos violentos por parte de estas personas. Por otra parte, la inmensa mayoría de ellos tampoco pudieron ver a su abogado hasta momentos antes de entrar en la sala de vistas (RUBIN, A. J. «France Hands ISIS Suspects to Iraq, Which Sentences Them to Hang», The New York Times, 29 de mayo de 2019, Disponible en [fecha de consulta: 5 de junio de 2020] https://www.nytimes.com/2019/05/29/world/middleeast/france-iraq-isistrials.html. Al margen de este juicio, hay constancia de otros que, siendo el resultado final una condena a pena de muerte, han tenido una duración de 10 minutos (COKER, M. y HaSSAN, F. «A 10-Minute Trial, a Death Sentence: Iraqi Justice for ISIS Suspects», The New York Times, 17 de abril de 2018, Disponible en [fecha de última consult: 8 de junio de 202] https://www.nytimes.com/2018/04/17/world/middleeast/iraq-isis-trials.html).

91 AmNistía InTERNACIONAL. "Informe Global de Amnistía Internacional. Condena a penas de muerte y ejecuciones». Amnistía Internacional, 2020.

92 Amnistía InTERnAcional. "Prisión siria de Saydnaya, un "matadero humano». Amnistía Internacional, 7 de febrero de 2017, Disponible en [fecha de última consulta: 10 de junio de 2020] https:/www.es.amnesty.org/en-que-estamos/blog/historia/articulo/ prision-siria-de-saydnaya-un-matadero-humano/.

93 En este sentido, de 198 países que evalúa el ranking, Irak ocuparía la posición 162 y Siria la 178 (TRANSPARENCy InTERnATIONAL. "Corruption Perceptions Index», Transparency International, Disponible en [fecha de última consulta: 8 de junio de 2020] https://www. transparency.org/es/cpi/2019/results/irq).

94 SANcha, N. "La ofensiva turca en Siria desata el miedo a la evasión de los yihadistas detenidos por los kurdos», El País, 11 de octubre de 2019, Disponible en [fecha de última consulta: 11 de junio de 2020] https:/elpais.com/internacional/2019/10/10/ actualidad/1570731504_715651.html. 
oleada con respecto a sus anteriores manifestaciones ha sido la movilización de familias enteras con la única pretensión de convertirse en ciudadanos del autoproclamado Estado Islámico ${ }^{95}$. En estos términos, una de las cuestiones que más se ha señalado es que algunas de las mujeres que ahora se encuentran en estos campos habrían sido coaccionadas por sus maridos para trasladarse a estos territorios, lo que tornaría en especialmente injusto cualquier tipo de castigo que se aplique contra ellas ${ }^{96}$.

En segundo lugar, siendo conscientes de los problemas que genera perseguir penalmente a los «combatientes terroristas extranjeros» por las autoridades sirias e iraquíes, también ha sido planteada -especialmente por los kurdos ${ }^{97}$ - la posibilidad de crear un Tribunal Penal Internacional al estilo de lo acontecido en Nuremberg para juzgar a los miembros del Estado Islámico al amparo de Naciones Unidas ${ }^{98}$. En este sentido, se ha argumentado que esta sería la opción más aconsejable para que estas personas puedan ser juzgadas en estos territorios y, al mismo tiempo, se garantice la existencia de un proceso justo donde los derechos humanos sean respetados ${ }^{99}$. Ahora bien, tal y como apuntan Mehra y Paulussen, esta opción plantea toda una serie de problemas que abarcan desde cuestiones políticas como la dificultad existente para conseguir el apoyo de todos los miembros del Consejo de Seguridad hasta otras de naturaleza legal fundamentalmente marcadas por la determinación de cuál debe ser la ley aplicable, pasando también por temas referidos a la gran cantidad de recursos que implicaría esta opción o a la exigencia de una cooperación internacional que no siempre está presente ${ }^{100}$. Además, también ha sido puesto en evidencia que juzgar únicamente a los miembros del Estado Islámico en este Tribunal Internacional implicaría una suerte de justicia selectiva que, por su parte, dejaría fuera a otros actores que han cometido atrocidades durante la contienda, ya sean otros grupos insurgentes, las fuerzas iraquíes, el régimen sirio o, incluso, las Fuerzas Democráticas Sirias con el amparo de la Coalición Internacional ${ }^{101}$.

95 Pokalova, E. Returning Islamist Foreing Fighters. Threats and Challenges to the West, op. cit., 2020, p.42.

96 Mehra, T. y Paulussen, C. "The Repatriation of Foreing Fighters and Their Families: Options, Obligations, Morality and Long-Term Thinking», op. cit.

97 Hurtado, L. M. «Los kurdos quieren que un tribunal internacional juzgue al Estado Islámico», El Mundo, 26 de marzo de 2019, Disponible en [fecha de última consulta: 11 de junio de 2020] https://www.elmundo.es/internacional/2019/03/26/5c9a4fac21efa0f016 8b4659.html.

98 Jenkins, B. M. «Options for Dealing with Islamic State Foreing Fighters Currently Detained in Syria», CTC SENTINEL, vol.12, núm.5, p.19.

99 Dworkin, A. «Beyond Good and Evil: Why Europe Should bring ISIS Foreing Fighters Home», op. cit., p.15.

100 Menra, T. y Paulussen, C. «The Repatriation of Foreing Fighters and Their Families: Options, Obligations, Morality and Long-Term Thinking», International Centre for Counter-Terrorism - The Hague, op. cit.

101 DworkIN, A. «Beyond Good and Evil: Why Europe Should bring ISIS Foreing Fighters Home», op. cit., p.15. 
Por último, la tercera alternativa disponible sería posibilitar el retorno de los «combatientes terroristas extranjeros». Para ello, existirían dos vías diferentes: por un lado, los Estados podrían permitir el regreso de aquellas personas que quieran hacerlo, pero sin involucrarse activamente en este regreso. En este sentido, cabe advertir que, si bien es cierto que algunos países han reconocido el derecho que tienen estas personas de retornar a sus países de origen, también lo es que estos no han contribuido a facilitar tal regreso de forma activa. Por ejemplo, en el caso holandés, el gobierno ha instado a sus nacionales a que acudan a las representaciones diplomáticas en la región para solicitar un posible retorno. No obstante, para Mehra y Paulussen, esta opción equivaldría a enseñar al detenido la llave de su celda y, al mismo tiempo, dejarla fuera de su alcance, puesto que, al estar privados de libertad, la inmensa mayoría de ellos no pueden seguir este procedimiento ${ }^{102}$. Por otra parte, también existe la posibilidad de que los Estados repatrien activamente a sus nacionales con la finalidad de que, en aquellos casos en los que sea posible, estos sean perseguidos penalmente por las autoridades nacionales. Aunque esta opción, al menos por el momento, ha sido marginal entre los países europeos debido a los problemáticas expuestas más arriba, existe constancia de que, en determinadas ocasiones, estos han repatriado activamente a algunos de sus nacionales, especialmente cuando se trata de menores ${ }^{103}$.

Ahora bien, existen importantes razones para pensar que, dentro del abanico de opciones disponibles, la repatriación activa de todos los «combatientes terroristas extranjeros»-también la de los hombres adultos- es la mejor de ellas tanto en lo que se refiere a la protección de los derechos humanos como en términos de seguridad. O, al menos, la que menos inconvenientes plantea. En este sentido, parece evidente que, actualmente, la repatriación activa es la única opción que ofrece ciertas

102 Mehra, T. y Paulussen, C. «The Repatriation of Foreing Fighters and Their Families: Options, Obligations, Morality and Long-Term Thinking», op. cit.

103 Por ejemplo, Francia repatrió recientemente a doce menores que, según el Ministro de Exteriores francés, se encontraban en una situación de especial vulnerabilidad y desprotección (AgENCE FrANCE-PRESSE. "Orphans of French Isis fighters fly home from Syria», The Guardian, 10 de junio de 2019, Disponible en [fecha de última consulta: 15 de junio de 2020] https://www.theguardian.com/world/2019/jun/10/syria-kurds-childrenorphans-french-isis-islamic-state-fighters-handed-over-france). En estos términos, los menores han sido mayoritariamente considerados como víctimas del conflicto. Sin embargo, su repatriación no ha sido siempre posible debido tanto a la oposición de la opinión pública como al hecho de que los kurdos han insistido en ligar estas repatriaciones con las de sus madres, siendo esta una línea roja para muchos gobiernos europeos (RENARD. T. y Coolsaet, R. «Losing Control Over Returnees?», op. cit.). PoKalova, además, señala que otras problemáticas existentes a la hora de repatriar a los menores vienen marcadas por cuestiones como la dificultad para determinar la nacionalidad de los menores o el hecho de dirimir quien debe asumir la custodia de los mismos una vez regresen a los países de origen. Para un mayor detalle, véase, PoKAlova, E. Returning Islamist Foreing Fighters. Threats and Challenges to the West, op. cit., p.211). 
garantías de que los derechos humanos de estas personas van a ser respetados, lo que ya se constituye en sí mismo como una poderoso argumento para que los Estados europeos apuesten por esta alternativa ${ }^{104}$. La voluntad de hacer que se respeten los derechos humanos, sin embargo, no es únicamente una suerte de imperativo moral sino que, además, esta también tiene raíces legales. De entrada, tanto la Resolución 2178 (2014) del Consejo de Seguridad de Naciones Unidas como la Resolución 2396 (2017) de este mismo órgano han puesto de relieve que los Estados tienen la obligación de formular y aplicar estrategias de enjuiciamiento, rehabilitación y reintegración de estas personas ${ }^{105}$. Además, ambas insisten en que estas acciones deben de quedar siempre inmersas dentro de los márgenes del Estado de Derecho ${ }^{106}$. Por otra parte, también ha sido señalado que, a través de los consulados, los Estados tienen la obligación de dar a asistencia a sus nacionales en el exterior ${ }^{107}$. Asimismo, en el caso de los menores, la Convención de los Derechos del niño establece en su artículo tercero que los Estados se comprometen a asegurar la protección y cuidados necesarios para su bienestar ${ }^{108}$, algo que de forma manifiesta no está teniendo lugar en los campos de detención situados al norte de Siria ${ }^{109}$.

Por otra parte, a pesar de que más arriba se ha sostenido que los retornados pueden llegar a constituirse como una importante amenaza para la seguridad de los países europeos, también es importante advertir que, paradójicamente, la repatriación activa de todos los «combatientes terroristas extranjeros» procedentes de Europa representa, al mismo tiempo, la opción más segura en la actualidad por varios motivos: en primer lugar, en un contexto donde los kurdos, ya sea por ausencia de infraestructuras o por la reciente ofensiva turca, tienen cada vez menos control sobre los campos de detención, la repatriación activa es el único medio disponible para garantizar el mantenimiento de un control adecuado sobre estas personas. En este sentido, Renard y Coolsaet advierten que, en caso de que escapasen o fuesen liberados, estos podrían contribuir al resurgimiento del Estado Islámico, viajar a otras zonas de conflic-

104 OscE. «Repatriation of foreing terrorist fighters and their families urgently needed to safeguard human rights and security, Osce human right head says», Organization for Security and Co-operation in Europe», Disponible en [fecha de consulta: 18 de junio de 2020] https://www.osce.org/odihr/445909.

105 En este sentido, véase, Resolución 2178 (2014) de 24 de septiembre de 2014, S/ RES/2178, p.5 y Resolución 2396 (2017) de 21de diciembre de 2017, p.12.

106 Sobre esta cuestión, la propia Resolución 2178 (2014) del Consejo de Seguridad de Naciones Unidas establece que no respetar el Estado de Derecho en la lucha contra el terrorismo se constituye como un factor que contribuye a potenciar la radicalización (Resolución 2178 (2014) de 24 de septiembre de 2014, S/RES/2178, p.2.).

107 Para un mayor detalle de las funciones consulares, véase, CONVENCIÓN DE VIENA Sobre Relaciones Consulares, de 24 de abril de 1963.

108 Convención Sobre Los Derechos Del Niño, de 20 de noviembre de 1989.

109 Mehra, T. y Paulussen, C. "The Repatriation of Foreing Fighters and Their Families: Options, Obligations, Morality and Long-Term Thinking», op. cit. 
to o, incluso, cometer atentados en los países occidentales sin que fuesen previamente detectados por las autoridades ${ }^{110}$. De otro lado, Pokalova señala que, si los gobiernos occidentales siguen manteniéndose en esta suerte de inacción, estos no estarían sino creando un sustrato adecuado para potenciar los procesos de radicalización acometidos ${ }^{111}$, especialmente en el caso de aquellos menores que se encuentran en los campos de detención ${ }^{112}$. Al final y al cabo, no se estaría ofreciendo ninguna vía de salida al margen del amparo que ofrece la organización, lo que indudablemente se constituye como un riesgo. Por último, en una dimensión más pragmática, Dworkin apunta a que estas personas podrían incluso llegar a colaborar con las agencias de seguridad una vez retornen ${ }^{113}$, además de ser útiles desde el punto de vista de la comunicación política para, a través de su ejemplo, evitar futuras movilizaciones a otras zonas de conflicto ${ }^{114}$.

De este modo, como se puede apreciar, la repatriación activa de todos los «combatientes terroristas extranjeros» ofrece unas mayores garantías frente a las otras opciones disponibles, tanto desde una dimensión puramente securitaria como en lo que se refiere a la exclusiva protección de los derechos humanos. Ahora bien, siempre que sea posible y existan evidencias de que la persona ha cometido un delito, debería abrirse un procedimiento penal para dirimir su responsabilidad. En otras palabras, aquí no se está proponiendo una suerte de inacción en sentido contrario -es decir, facilitar el regreso de los «combatientes terroristas extranjeros» sin aplicar otras medidas complementarias- sino simplemente aplicar el Derecho, con todas las consecuencias que de ello se deriva.

110 Renard. T. y CoOlsaet, R. «Losing Control Over Returnees?», op cit.

111 PoKalova, E. Returning Islamist Foreing Fighters. Threats and Challenges to the West, p.211.

${ }_{112}$ Martinez, S. «Europa esquiva la repatriación de los hijos de los yihadistas», El Periódico, 17 de noviembre de 2019, Disponible en [fecha de última consulta: 22 de junio de 2020] https://www.elperiodico.com/es/internacional/20191115/europa-calla-frente-a-larepatriacion-de-los-hijos-de-los-yihadistas-europeos-7737692.

113 Dworkin, A. «Beyond Good and Evil: Why Europe Should bring ISIS Foreing Fighters Home», op. cit., p.15.

114 Este habría sido, por ejemplo, el caso de Henry Sarfo, un ciudadano alemán que, tras abandonar las filas de la organización, ha colaborado ampliamente con las agencias de seguridad y en repetidas entrevistas ha narrado su mala experiencia con el DAESH (Gladstone, R. "German ISIS Member Who Denied Killing is Charged in Murders», The New York Times, 3 de junio de 2017, Disponible en [fecha de última consulta: https://www. nytimes.com/2017/01/03/world/europe/harry-sarfo-isis-germany.html]). 


\section{Una paradoja llamativa: ¿reclamando la aplicación de un «Derecho Penal del enemigo» para proteger los derechos humanos?}

La RES 2178 del Consejo de Seguridad de Naciones Unidas inicia su fundamentación expresando su «grave preocupación por la grave y creciente amenaza que plantean los combatientes terroristas extranjeros, a saber, las personas que viajan a un Estado distinto de su Estado de residencia o nacionalidad con el propósito de cometer, planificar o preparar actos terroristas o participar en ellos, o de proporcionar o recibir adiestramiento con fines de terrorismo, incluso en relación con conflictos armados». A lo que añade una preocupación específica "porque los terroristas y las entidades terroristas han establecido redes internacionales entre los Estados de origen, tránsito y destino, a través de las cuales se mueven en una y otra dirección los combatientes terroristas extranjeros y los recursos para apoyarlos», y porque «los combatientes terroristas extranjeros están siendo reclutados por entidades como el Estado Islámico de Iraq y el Levante (EIIL), el Frente Al-Nusra y otras células, entidades afiliadas o grupos escindidos o derivados de Al-Qaida».

Como se ha señalado, los combatientes extranjeros, es decir, los sujetos que se desplazan a otro país distinto al suyo para participar en un conflicto armado, no son un fenómeno nuevo. Sin embargo, la Resolución acepta como categoría autónoma la de combatiente terrorista extranjero, que representa, según señala Jiménez García ${ }^{115}$, una suerte de oxímoron jurídico, en el que se yuxtaponen dos conceptos hasta ahora diferenciados: los combatientes, que como parte de un conflicto quedan inmersos en las normas que lo regulan, entre ellas el Derecho Internacional Humanitario (DIH), y los terroristas, sujetos al Derecho Penal del terrorismo. Por otra parte, la Resolución se dirige directamente a los combatientes terroristas extranjeros, actores no estatales, para que depongan las armas, así como a los Estados, imponiendo:

«que todos los Estados se cercioren de que sus leyes y otros instrumentos legislativos internos tipifiquen delitos graves que sean suficientes para que se pueda enjuiciar y sancionar de modo que quede debidamente reflejada la gravedad del delito:

a. A sus nacionales que viajen o intenten viajar a un Estado distinto de sus Estados de residencia o nacionalidad, y demás personas que viajen o intenten viajar desde sus territorios a un Estado distinto de sus Estados de residencia o nacionalidad, con el propósito de cometer, planificar

115 Jiménez García, F., «Combatientes Terroristas Extranjeros y conflictos armados: utilitarismo inmediato ante fenómenos no resueltos y normas no consensuadas», op. cit., p. 280 . 
o preparar actos terroristas o participar en ellos, o proporcionar o recibir adiestramiento con fines de terrorismo;

b. La provisión o recaudación intencionales de fondos, por cualquier medio, directa o indirectamente, por sus nacionales o en sus territorios con intención de que dichos fondos se utilicen, o con conocimiento de que dichos fondos se utilizarán, para financiar los viajes de personas a un Estado distinto de sus Estados de residencia o nacionalidad con el propósito de cometer, planificar o preparar actos terroristas o participar en ellos, o proporcionar o recibir adiestramiento con fines de terrorismo; $y$,

c. La organización u otro tipo de facilitación deliberadas, incluidos actos de reclutamiento, por sus nacionales o en sus territorios, de los viajes de personas a un Estado distinto de sus Estados de residencia o nacionalidad con el propósito de cometer, planificar o preparar actos terroristas o participar en ellos, o proporcionar o recibir adiestramiento con fines de terrorismo»

La Reforma del Código penal español de 2015 (LO 2/2015, de 30 de marzo, por la que se modifica la LO 10/1995, de 23 de noviembre, del Código Penal, en materia de delitos de terrorismo), apela en su preámbulo a la Resolución 2178 del Consejo de Seguridad, y destaca la necesidad de adecuar la legislación penal española al terrorismo de corte yihadista. Sin embargo, nuestro Código penal ya era uno de los más duros en la represión del terrorismo: además de la tipificación del terrorismo individual, el antiguo artículo 576.2 CP castigaba como delito de colaboración con organización o grupo terrorista a «cualquier equivalente cooperación, ayuda o mediación, económica o de otro género con las actividades del grupo u organización», cláusula abierta (similar a la contenida en el actual 577.1 CP) que permitía incluir actividades de colaboración realizadas desde fuera de la organización criminal con enorme amplitud. No obstante, las novedades más llamativas en la Reforma de 2015 se refieren a la exclusión expresa de la exigencia del elemento organizativo en la definición del terrorismo y a la tipificación, en el nuevo artículo 575 $\mathrm{CP}$, de distintas conductas relacionadas con el llamado adoctrinamiento pasivo (núms. 1 y 2, incluyendo el «autoadoctrinamento») y los viajes a territorios extranjeros, con la finalidad de capacitarse para llevar a cabo delitos de terrorismo, para cometerlos, o para colaborar con organizaciones terroristas (núm. 3).

La Ley Orgánica 1/2019, de 20 de febrero, por la que se modifica la Ley Orgánica 10/1995, de 23 de noviembre, del CP, invocando la transposición de la Directiva 2017/541 del Parlamento Europeo y del Consejo de 15 de marzo de 2017, relativa a la lucha contra el terrorismo, eleva la pena para los directores de los grupos terroristas (el límite máximo de la pena de prisión pasa de 14 a 15 años, y se sustituye la inhabilitación especial por la inhabilitación absoluta), y para los que participan activamente en la misma (estableciendo igualmente la inhabilitación absoluta); 
añade la falsedad documental a la enumeración de delitos recogidos en el art. 573.1 CP y que deberían representar el sector «nuclear» de las actividades terroristas (pero que finalmente desbordan lo entendido en este concepto); y elimina la exigencia de que el territorio al que se traslada el combatiente esté controlado por un grupo terrorista (art. 575. 3 CP).

La primera reflexión crítica que suscita este modelo punitivo es que sin duda representa una restricción de la libertad ambulatoria a través del adelantamiento de la intervención penal a una fase de preparación ${ }^{116}$. Ahora bien, siendo esto cierto, no lo es menos, como apunta Campo Moreno ${ }^{117}$, que los desplazamientos de los sujetos para integrarse en grupos terroristas o las conductas de financiación o coordinación de infraestructuras para la captación de miembros de las organizaciones terroristas ya podían ser castigadas a través de los delitos de integración o colaboración, tipificados en el Código penal español con anterioridad a la reforma de $2015^{118}$. Es decir, con independencia de la valoración que merezca la punición específica de una conducta que claramente se encuentra en una fase de preparación, sería un error concluir que esta posibilidad de sanción haya aparecido con la reforma de 2015: el CP español admite el castigo de la participación en integración en grupo terrorista (art. 572) $)^{119}$ o de colaboración (art. 577) ${ }^{120}$, con tal amplitud, que ya podía llegarse a la sanción de estos comportamientos a través de estos preceptos.

116 En este sentido, Garrido MuÑoz, A., «Un nuevo cortocircuito legislativo en Naciones Unidas: la Resolución 2178 (2014) del Consejo de Seguridad de Naciones Unidas relativa a los combatientes terroristas extranjeros», Revista Española de Derecho Internacional, núm. 67, p. 306; JimÉnEz GARCÍA, F., «Combatientes Terroristas Extranjeros y conflictos armados: utilitarismo inmediato ante fenómenos no resueltos y normas no consensuadas», op. cit., p. 289; NúÑEZ CASTAÑo, E. «Algunas consideraciones sobre la transposición al Derecho Penal español de la Directiva 2017/541/UE del Parlamento europeo y del Consejo, en materia de terrorismo: ¿una tarea necesaria?», en González Cano, M.I. (dir.), Integración europea y justicia penal, Valencia, 2018, Tirant lo blanch, p. 270; PÉREz CEPEDA, A.I., El pacto antiyihadista: criminalización de la radicalización, op. cit., p. 280 .

117 Campo Moreno, J., Comentarios a la reforma del Código Penal en materia de terrorismo, Valencia, Tirant lo Blanch, 2016, p. 63.

118 De forma crítica contra la interpretación extensiva de los delitos de integración y colaboración, concluye GIL GIL, A., «La expansión de los delitos de terrorismo en España a través del delito de pertenencia a organización terrorista», en Ambos, K., Malarino, E. y Steiner, C., (coords.), Terrorismo y Derecho Penal), Bogotá, 2015, Konrad Adenauer, pp. 358-359.

119 Artículo 572 CP:

«1. Quienes promovieran, constituyeran, organizaran o dirigieran una organización o grupo terrorista serán castigados con las penas de prisión de ocho a catorce años e inhabilitación especial para empleo o cargo público por tiempo de ocho a quince años.

2. Quienes participaran activamente en la organización o grupo, o formaran parte de ellos, serán castigados con las penas de prisión de seis a doce años e inhabilitación especial para empleo o cargo público por tiempo de seis a catorce años.»

120 El art. 577 CP dispone:

«1. Será castigado con las penas de prisión de cinco a diez años y multa de dieciocho a veinticuatro meses el que lleve a cabo, recabe o facilite cualquier acto de colaboración con 
Un análisis de las sentencias de la Audiencia Nacional y del Tribunal Supremo español, entre los años 2010 y 2020, confirma esta percepción, ya que la mayoría de los casos de traslado o de organización y financiación de los viajes han sido castigados con las penas contempladas en los arts. 572 y 577 del CP (es decir, por integración o colaboración respectivamente). En este período sólo se han dictado dos sentencias condenatorias por el delito de traslado a territorio extranjero con fines terroristas. La SAN 31/2018, de 15 de octubre, castiga a un sujeto que se desplaza hasta Turquía con la intención de integrarse en el ISIS y es detenido en este país (en la ciudad de Kilis), en la frontera con Siria, por tentativa de traslado (art. 575.3 CP), al que añade la responsabilidad por un delito de autoadoctrinamiento (art. 575.2 CP) en concurso real. Por su parte, la SAN 29/2017, de 30 de noviembre, castiga por traslado a una mujer que había intentado viajar a Siria con su pareja en dos ocasiones (octubre y noviembre de 2015), siendo detenidos en Estambul, con una pena de dos años, en juicio de conformidad (el varón es encarcelado en Marruecos).

las actividades o las finalidades de una organización, grupo o elemento terrorista, o para cometer cualquiera de los delitos comprendidos en este Capítulo.

En particular son actos de colaboración la información o vigilancia de personas, bienes o instalaciones, la construcción, acondicionamiento, cesión o utilización de alojamientos o depósitos, la ocultación, acogimiento o traslado de personas, la organización de prácticas de entrenamiento o la asistencia a ellas, la prestación de servicios tecnológicos, y cualquier otra forma equivalente de cooperación o ayuda a las actividades de las organizaciones o grupos terroristas, grupos o personas a que se refiere el párrafo anterior.

Cuando la información o vigilancia de personas mencionada en el párrafo anterior ponga en peligro la vida, la integridad física, la libertad o el patrimonio de las mismas se impondrá la pena prevista en este apartado en su mitad superior. Si se produjera la lesión de cualquiera de estos bienes jurídicos se castigará el hecho como coautoría o complicidad, según los casos.

2. Las penas previstas en el apartado anterior se impondrán a quienes lleven a cabo cualquier actividad de captación, adoctrinamiento o adiestramiento, que esté dirigida o que, por su contenido, resulte idónea para incitar a incorporarse a una organización o grupo terrorista, o para cometer cualquiera de los delitos comprendidos en este Capítulo.

Asimismo, se impondrán estas penas a los que faciliten adiestramiento o instrucción sobre la fabricación o uso de explosivos, armas de fuego u otras armas o sustancias nocivas o peligrosas, o sobre métodos o técnicas especialmente adecuados para la comisión de alguno de los delitos del artículo 573, con la intención o conocimiento de que van a ser utilizados para ello.

Las penas se impondrán en su mitad superior, pudiéndose llegar a la superior en grado, cuando los actos previstos en este apartado se hubieran dirigido a menores de edad o personas con discapacidad necesitadas de especial protección o a mujeres víctimas de trata con el fin de convertirlas en cónyuges, compañeras o esclavas sexuales de los autores del delito, sin perjuicio de imponer las que además procedan por los delitos contra la libertad sexual cometidos.

3. Si la colaboración con las actividades o las finalidades de una organización o grupo terrorista, o en la comisión de cualquiera de los delitos comprendidos en este Capítulo, se hubiera producido por imprudencia grave se impondrá la pena de prisión de seis a dieciocho meses y multa de seis a doce meses.» 
Esta constatación no avoca a una conclusión definitiva sobre la conveniencia de adelantar la intervención hasta esta fase ni sobre la preferencia por la aplicación de un tipo u otro. Pero advierte que la tipificación expresa del traslado en España no ha representado un endurecimiento en el tratamiento penal, sino que más bien ha confirmado que la regulación vigente desde 2010 sobre integración y colaboración ya procuraba un marco interpretativo que acogía el adelantamiento y la exasperación de la intervención. Este modelo punitivo ha recibido numerosas críticas entre la doctrina penal española, siendo tal vez la posición de Paredes Castañón ${ }^{121}$ la más abiertamente contraria a la regulación vigente. En opinión de Paredes, el debate sobre el terrorismo se ha visto concernido, especialmente tras los ataques de septiembre de 2001 en EEUU, en un contexto de "pánico moral», fenómeno sociológico definido por Stanley Cohen en $1972^{122}$ en el que, ante la existencia de problemas complejos, la interacción de ansiedad y miedo colectivo proyecta una reacción de pánico caracterizada por la definición en términos simples (no verificados, que invocan estereotipos) y en clave de conflicto del objeto de análisis: se magnifica la proporción del daño que se atribuye a individuos desviados y hostiles que han de ser eliminados. Según Paredes, la aplicación de este esquema al debate sobre el terrorismo ha concluido con una exageración del riesgo objetivo de los hechos calificados como terroristas (al menos para la población occidental), sin que quepa apreciar una lesividad relevante de tipo colectivo (como la estabilidad del sistema político), más allá del daño causado a los bienes jurídicos individuales a través de los actos terroristas concretos. Bajo esta perspectiva, Paredes propone la supresión de la mayor gravedad de los delitos de terrorismo propiamente dichos (arts. 573 y $574 \mathrm{CP}$ ), que se castigarían a través de los correspondientes delitos comunes (homicidio, asesinato, lesiones, detenciones ilegales, etc.); el castigo de la integración en organización terrorista a partir del delito de integración en organización criminal (arts. 571 y $572 \mathrm{CP}$ ); la reforma y acotación del delito de colaboración (art. $577 \mathrm{CP}$ ); la supresión del enaltecimiento del terrorismo (art. $578 \mathrm{C}$ ); en todo caso, la supresión de los nuevos delitos de autoadoctrinamiento, traslado, colaboración imprudente e incitación $(\text { arts. } 575,577.3 \text { y } 579 \mathrm{CP})^{123}$.

Tiene razón Paredes Castañón al advertir que el miedo es un elemento esencial en la evaluación del terrorismo, así como que en destacar la

121 Paredes CASTAÑón, J.M. «Una modesta proposición para derogar los delitos de terrorismo (o casi)», en Pérez Cepeda, A.I./Portilla Contreras, G. (dir), Terrorismo y contraterrorismo en el siglo XXI. Un análisis penal y político criminal, España, 2016, Ratio Legis, pp. $61-86$.

122 Cohen S., Folk Devils and Moral Panics. The creation of the Mods and Rockers, $5^{\mathrm{a}}$ ed., Abingdon, 2011, Taylor \& Francis e-Library.

123 Paredes CASTAÑón, J.M., «Una modesta proposición para derogar los delitos de terrorismo (o casi)», op. cit., 72-86. 
ansiedad como emoción relevante en un proceso en el que no se atisba una solución inmediata. Asimismo, es también cierto que la incapacidad para encontrar vías de resolución, a nivel político y también en el plano científico, favorece la explicación de la desviación, del enemigo, del fanático. Este proceso está intrincado en el análisis del terrorismo a diversos niveles, sustentando tópicos que enturbian el diagnóstico: la «radicalización» como factor esencial en la determinación del fenómeno, la consideración de la ideología «terrorista» como un uniforme discurso irracional es la definición del terrorista como enemigo global deshumanizado o la comprensión del mismo como un "fanático», sobre el que no caben estrategias de prevención o rehabilitación, entre otros. Sin embargo, asimilar los procesos de cazas de brujas de corte ideológico, sobre los que esencialmente Cohen formuló su teoría del pánico moral, con el fenómeno del terrorismo internacional, puede conducir a otra clase de simplificaciones, con resultados indeseables. Los terroristas atacan derechos fundamentales de las personas, la vida, la integridad física, la libertad, de forma aleatoria y brutal. No sólo es lícito que estas acciones produzcan miedo, rechazo, sino que es lo que cabe esperar. Se trata de atentados indiscriminados contra bienes jurídicos esenciales, que despiertan valiosos sentimientos de empatía y temor. Suscitan consecuencias indirectas adicionales de grave repercusión: generan razonablemente una desconfianza sobre la capacidad del Estado para proteger bienes esenciales; provocan una reacción de autoritarismo; abonan la legitimidad de las vías de hecho, al margen de los cauces democráticos. Esta secuencia de resultados no se produce en todo caso con la misma intensidad, pero su realidad es empíricamente demostrable. No es, solo, una elaboración socio cultural o política. El terrorismo yihadista internacional, por otra parte, se ha propuesto una estrategia de desestabilización global, con graves repercusiones colectivas, a través de la infiltración en conflictos internos en Estados africanos y asiáticos, provocando el aumento en la intensidad y la duración de las guerras y contribuyendo de manera clara al desmantelamiento de frágiles estructuras estatales.

En este contexto sería un error plantear una definición de terrorismo desde una perspectiva nacional o regional. El terrorismo yihadista se ha convertido en un fenómeno global dinámico y proactivo que exige amplitud de miras en el diseño de las políticas, también de las penales. Como destaca Cancio Meliá, el punto de partida ha de ser la advertencia de su significación política, construida en la premisa de la legitimidad de la violencia para la destrucción de los sistemas políticos, instrumentalizando a los individuos a través de la intimidación masiva ${ }^{124}$, y sobre dicha especificidad, la construcción de una respuesta penal específica no

124 Cancio Melia, M., «El concepto jurídico - penal de terrorismo entre la negación y la resignación», en Alonso Rimo, A./Cuerda Arnau, M.L./ Fernández Hernández, A. (dir), Terrorismo, sistema penal y derechos fundamentales, Valencia, 2018, Tirant lo Blanch, pp. 103-110. 
tiene por qué representar la apuesta por un nivel de represión superior. Siguiendo también en esto a Cancio, como por otra parte se ha advertido en la primera parte del trabajo, la renuncia al Derecho Penal podría conducir a la prevalencia de las vías de hecho ${ }^{125}$ : la guerra al terrorismo, el recurso a la legítima defensa preventiva y la proliferación de los ataques con drones o los asesinatos selectivos.

En el ámbito del Derecho Internacional el recurso a la legítima defensa ha sido impulsado por Israel y EEUU especialmente a partir de los ataques de septiembre de 2001 (también por Francia, después de los atentados de DAESH en su territorio, en 2013 y 2015, o por Rusia y Turquía, con un expresivo silencio por parte del resto de los Estados). Tras estos actos terroristas, la Resolución 1368 del Consejo de Seguridad de $\mathrm{UN}^{126}$, expresa en su preámbulo su decisión «a combatir por todos los medios las amenazas a la paz y la seguridad internacionales creadas por actos de terrorismo» y reconoce el derecho inmanente de legítima defensa individual o colectiva de conformidad con la Carta de las Naciones Unidas, formulación que ha impulsado el debate sobre los límites del recurso a la legítima defensa. En este sentido, la Carta de Naciones Unidas anuda el derecho a la legítima defensa a la existencia de un «ataque armado», lo que impediría la utilización de este instrumento de manera preventiva. Por otra parte, la Corte Internacional de Justicia ha exigido que el ataque provenga de un Estado. Estos dos requisitos dificultarían, en sentido estricto, la utilización de la legítima defensa frente al terrorismo. Sin embargo, la pretensión esgrimida por DAESH de constituirse en un Estado ha favorecido la interpretación de que el nuevo terrorismo yihadista se está sirviendo de estructuras pseudoestatales frente a las que es posible reaccionar en legítima defensa ${ }^{127}$. Las vías de hecho utilizadas por los Estados a favor de esta interpretación representan, en opinión de algunos autores, la confirmación de que las restricciones impuestas

125 Cancio Melia, M., «El concepto jurídico - penal de terrorismo entre la negación y la resignación», op. cit., pp. 105-106.

126 S/RES/1368 (2001), aprobada por el Consejo de Seguridad en su 4370a sesión, celebrada el 12 de septiembre de 2001.

127 Precisamente, Francia ha invocado la aplicación el artículo 42.7 del Tratado de la Unión Europea tras los atentados en Paris de 13 de noviembre de 2013, y después de declararse «en guerra» contra el DAESH. Este artículo recoge la llamada «cláusula de defensa mutua» entre los países de la Unión Europea, posición que fue respaldada por los Gobiernos de la Unión. Es preciso tener en cuenta que el art. 42.7 establece esa obligación cuando un Estado Miembro es víctima de agresión armada en su territorio, lo que determinaría la asistencia del resto a través de todos los medios a su alcance (véase el resumen del caso francés por Pol Morillas en la página del Centre for international affairs de Barcelona:

https://www.cidob.org/publicaciones/serie_de_publicacion/opinion/europa/el_42_7_ cobertura_europea_para_la_defensa_francesa). También GouTTEFARDE, F. «L'invocation de l'article 42.7 TUE ou la solidariste militaire européenne à l'épreuve de la guerre contre le terrorismo", Revue generale de droit international public, Vol. 129, núm. 1, 2016, pp. 51-63. 
por las resoluciones de la Corte Internacional de Justicia no se sustentan frente al avance y dimensión del terrorismo yihadista ${ }^{128}$, por lo que sería la «propia realidad» la que impondría el cambio. Sin embargo, la mayoría de la doctrina internacionalista en España no aprueba que las vías de hecho se impongan sobre el Derecho y consideran que esta posición representa una distorsión del derecho a la legítima defensa ${ }^{129}$.

En el campo del Derecho Penal, Silva Sánchez se opone a la utilización de la doctrina de la war on terror como base para el empleo de la legítima defensa preventiva: desde la concepción penal la reacción en legítima defensa requiera la actualidad o inminencia de la agresión. Sin embargo, admite la posibilidad de justificar los asesinatos selectivos (también los realizados a través de ataques con drones), invocando la posibilidad de legítima defensa frente a individuos, los integrados en un grupo terroristas, que forman para de una organización que constituye una agresión permanente para el modo de vida de una determinada socie$\mathrm{dad}^{130}$.

Sin embargo, como han sostenido entre otros Ferrajoli ${ }^{131}$ o Mir Puig ${ }^{132}$, la única estrategia legítima desde los Estados de Derecho consiste en utilizar, precisamente, las vías del Derecho, oponiendo su reafirmación frente a la destrucción pretendida por el terrorismo. En palabras de Ferrajoli, «la violencia terrorista ... es de hecho reconocible como criminalidad, y como tal despotenciable políticamente y deslegitimable jurídicamente, sólo si es tratada con el lenguaje y con las formas del derecho: con la determinación de las responsabilidades, con las garantías del debido proceso, con la aplicación de las penas previstas por la ley»133. Desde esta aseveración, no hay duda de que la repatriación de los «combatientes terroristas extranjeros» y su enjuiciamiento para la aplicación del Derecho penal vigente es la única solución legítima en este momento, sin que esto resulte incompatible con la reclamación de dos aspiraciones

128 En esta línea, Bermejo García, R. «Las denominadas nuevas tendencias en la lucha contra el terrorismo internacional. El caso del Estado Islámico», Anuario español de derecho internacional, núm. 33, 2017, pp. 51-61.

129 Jiménez García, F. "Combatientes Terroristas Extranjeros y conflictos armados: utilitarismo inmediato ante fenómenos no resueltos y normas no consensuadas», op. cit., pp. 298-300; SALINAS DE FríAS, A. «Lucha contra el terrorismo internacional. No solo del uso de la fuerza pueden vivir los Estados", Revista española de derecho internacional, vol. 68, núm. 2, 2016, pp. 242-244.

130 Silva SÁNCHEZ, J.M. "Asesinatos selectivos en la 'guerra punitiva' contra el terrorismo», InDret. Revista de Análisis para el Derecho, núm.1, 2017, pp.13-14.

131 Ferrajoli, L. "Guerra y terrorismo internacional. Un análisis del lenguaje jurídico», Anuario Mexicano de Derecho Internacional, vol. IX, 2009, pp. 29-31.

132 Mir PUIG, S. «Principio de proporcionalidad y fines del derecho penal», en Echano Basaldúa, J.I, Estudios jurídicos en memoria de José María Lidón, 2002, pp. 349-366, Universidad de Deusto, p. 350.

133 Ferrajoli, L. «Guerra y terrorismo internacional. Un análisis del lenguaje jurídico», op,cit., p. 29. 
que insisten en la búsqueda de la mayor legitimidad posible: la construcción de un concepto de terrorismo internacional y su inclusión en la materia propia de la jurisdicción de las cortes penales internacionales (aspecto que no ha sido posible abordar en este espacio); la depuración de un Derecho nacional contraterrorista exasperado e irracional en su intervención. En esta dirección, cabe afirmar, tras el recorrido de los mismos en los tribunales españoles, que los delitos de autoadoctrinamiento y enaltecimiento resultan intervenciones injustificadas en las libertades sin que hayan contribuido realmente a una mayor eficacia en la política antiterrorista. En segundo lugar, cabría someter a una mayor racionalidad la conducta de actividades de colaboración con el terrorismo, eliminando de una vez por todas las fórmulas generales y aplicando criterios de proporcionalidad en la previsión de la pena. En esta línea, la tipificación expresa, con pena menor que la prevista para la colaboración genérica, de los viajes de los CTE, no tiene por qué resultar una medida desproporcionada, sino lo contrario, siempre y cuando se limite el ámbito de aplicación del tipo en dos direcciones: el castigo del viaje debería reservarse para los casos en los que se demuestre la finalidad del sujeto de integrarse en un grupo terrorista (es decir, de participar activamente en atentados, no sólo de colaborar), que además haya alcanzado una especial lesividad al poseer un control territorial y una clara vocación expansiva.

\section{Conclusiones}

En definitiva, tal y como se ha podido apreciar a lo largo del presente artículo, la situación actual de los «combatientes terroristas extranjeros» remite a un panorama muy complejo en el que, tanto desde un punto de vista que promocione la consecución de la seguridad por encima de todo como en lo que se refiere de forma exclusiva a la protección de los derechos humanos, su repatriación activa se presenta como la mejor opción dentro del abanico de alternativas disponibles para los países europeos. Sin embargo, según se ha argumentado, esto no implicaría una suerte de inacción en sentido contrario sino que, siempre que sea posible y exista evidencia de que han cometido delitos de terrorismo, estas personas deben ser perseguidas penalmente. Al fin y al cabo, lo que se está aquí proponiendo no es sino la simple y llana aplicación del Derecho, con todas las consecuencias que de ello se derivan y también de las garantías que justifican su existencia. Ahora bien, antes de finalizar, resulta conveniente enfatizar que, si bien es cierto que el Derecho -por muy mejorable que sea- es siempre preferible al no-derecho, esto no significa que este sea el único medio disponible para enfrentar la problemática descrita. Por el contrario, en consonancia con lo establecido por el Consejo de Seguridad de Naciones Unidas en sus diferentes resoluciones, es estrictamente necesario desarrollar una respuesta integral que, antecediendo 
y trascendiendo al Derecho Penal, abarque cuestiones tan amplias como, por ejemplo, la intervención sobre los factores sociopolíticos que nutren el terrorismo, la prevención de la aparición del extremismo violento o, en un sentido más específico, la rehabilitación y la reintegración social de los «combatientes terroristas extranjeros».

\section{Bibliografía}

Acale Sánchez, M. «Terrorismo y tratamiento punitivista: más allá de la prisión», en (Pérez Cepeda, A. I., Dir.) El terrorismo en la actualidad: un nuevo enfoque político criminal, Tirant lo Blanch, Valencia, 2018.

AFP. «Irak juzgará a 13 franceses del Estado Islámico», La Vanguardia, Disponible en

[FECHA DE CONSULTA: 5 DE JUNIO DE 2020] HTTPS://WwW.lavanguardia.com/ internacional/20190226/46696142821/irak-juzgara-franceses-estadoislamico.html.

AGENCE FRANCE-PRESSE. "Orphans of French Isis fighters fly home from Syria», The Guardian, 10 de junio de 2019, Disponible en [fecha de última consulta: 15 de junio de 2020] https:/www.theguardian.com/ world/2019/jun/10/syria-kurds-children-orphans-french-isis-islamicstate-fighters-handed-over-france.

Altozano, M. "11 años y medio de cárcel a un expreso de Guantánamo por mandar voluntarios a Siria», El Confidencial, 28 de septiembre de 2016, Disponible en [fecha de última consulta: 28 de mayo de 2020 https://www.elconfidencial.com/espana/2016-09-28/11-anos-y-mediode-carcel-a-un-expreso-de-guantanamo-por-mandar-voluntarios-asiria_1267271/.

AMNISTÍA INTERNACIONAL. «Informe Global de Amnistía Internacional. Condena a penas de muerte y ejecuciones». Amnistía Internacional, 2020.

AMnistía InTERnAcional. "Prisión siria de Saydnaya, un «matadero humano». Amnistía Internacional, 7 de febrero de 2017, Disponible en [fecha de última consulta: 10 de junio de 2020] https://www. es.amnesty.org/en-que-estamos/blog/historia/articulo/prision-siria-desaydnaya-un-matadero-humano/.

AwAN, I. «Muslim Prisoners, Radicalization and Rehabilitation in British Prisons», Journal of Muslim Minority Affairs, 3, 2013, pp.371-384.

Bakker, E., Paulussen, C. Y Entenmann, E. «Returning Jihadist Foreing Fighters. Challenges Pertaining to Threat Assessment and Governance of this Pan-European Problem», Security and Human Rights, núm.25, 2015, pp.11-32. 
BARRET, R. «Beyond the Caliphate: Foreing Fighters and the Threat of Returnees», The Soufan Center, 2017.

Bвс. «Brussels Jewish Museum: Mehdi Nemmouched jailed for life», $B B C, 12$ de marzo de 2019, Disponible en [fecha de consulta: 26 de mayo de 2020] https://www.bbc.com/news/world-europe-47533533.

BERMEJO GaRcíA, R. "Las denominadas nuevas tendencias en la lucha contra el terrorismo internacional. El caso del Estado Islámico», Anuario español de derecho internacional, núm. 33, 2017, pp. 9-67.

Boutin, B. «Administrative Measures against Foreing Fighters: In Search of Limits and Safeguards", International Centre for Counter-Terrorism-The Hague, 2016, pp.1-35.

Boutin, B., Chauzal, G., Dorsey, J., Jegerings, M., Paulussen, C., Pohl, J., Reed, A., Zavagli, S. "The Foreing Fighters Phenomenon in the European Union», International Centre for Counter-Terrorism-The Hague, ICCT Research Paper, 2016, pp.1-149.

BurEs, O. «Eu's Response to Foreing Fighters: New Threat, Old Challenges?», Terrorism and Political Violence, 2018, pp.1-18.

Byman, D. «The homecomings: What Happens When Arab Foreing Fighters in Iraq and Syria Return», Studies in Conflict and Terrorism, vol.38, 20150 núm.8, pp.1-22.

Byman, D. Y Shapiro, J. «Be Afraid. Be A Little Afraid: The Threat of Terrorism from Western Foreing Fighters in Syria and Iraq», Foreing Policy at Brookings, Policy Paper, núm. 34, 2014.

Campo Moreno, J.c. Comentarios a la reforma del Código Penal en materia de terrorismo, Valencia, Tirant lo Blanch, 2016.

Cancio Meliá, M. «El concepto jurídico - penal de terrorismo entre la negación y la resignación», en Alonso Rimo, A./Cuerda Arnau, M.L./ Fernández Hernández, A. (dir), Terrorismo, sistema penal y derechos fundamentales, Tirant lo Blanch, Valencia, 2018, pp. 94-134.

CARO, L. «El Gobierno se resiste a repatriar a los españoles yihadistas en Siria para que se les juzgue allí», ABC España, 25 de octubre de 2019, Disponible en [fecha de última consulta: 21 de mayo de 2020], https:// www.abc.es/espana/abci-gobierno-resiste-repatriar-espanoles-yihadistas-siria-para-juzgue-alli-201910242217_noticia.html.

CEBRIáN, P. «¿Horca o cárcel iraquí? El incierto destino de los 57 yihadistas españoles detenidos en Siria», El Confidencial, 2 de agosto de 2019, Disponible en [fecha de última consulta: 1 de junio de 2020] https:/www.elconfidencial.com/mundo/2019-08-02/destino-yihadistas-espanoles-detenidos-siria_2158327/.

Cillufo, F. J., Cozzens, J. B. Y Ranstorp, M. «Foreing Fighters. Trends, Trajectories \& Conflict Zones», Homeland Security Police Institute, 2010, pp.1-40. 
Cillufo, F. Y Saathoff, G. "Out of the Shadows. Getting ahead of prisoner radicalization», The George Washington Homeland Security Policy Institute, Special Report, 2006, pp.1-38.

CoHen S., Folk Devils and Moral Panics. The creation of the Mods and Rockers, $5^{\mathrm{a}}$ ed., Abingdon, 2011, Taylor \& Francis e-Library.

Coker, M. Y Hassan, F. «A 10-Minute Trial, a Death Sentence: Iraqi Justice for ISIS Suspects», The New York Times, 17 de abril de 2018, Disponible en [fecha de última consult: 8 de junio de 202] https:// www.nytimes.com/2018/04/17/world/middleeast/iraq-isis-trials.html.

Convención De Viena Sobre Relaciones Consulares, De 24 De Abril De 1963.

Convención Sobre Los Derechos Del Niño, De 20 De Noviembre De 1989.

Coolsaet, R. Y Renard, T. "New Figures on European Nationals Detained in Syria and Iraq», Egmont Royal Institute for International Relations, 2019, Disponible en [fecha de última consulta: 21 de mayo de 2020] http://www.egmontinstitute.be/new-figures-on-europeannationals-detained-in-syria-and-iraq/).

Coolsaet, T. Y Renard, T. "How Belgium Overcame the Threat from Returing Foreing Terrorist Fighters», Egmont Royal Institute for International Relations, Comentarios, 22 de marzo de 2018, Disponible en [fecha de última consuta: 27 de mayo de 2020] http://www.egmontinstitute.be/how-belgium-overcame-the-threat-from-returningforeign-terrorist-fighters/.

CRAGIN, K. R. «The Challenge of Foreing Fighter Returnees», Journal of Contemporary Criminal Justice, 2017, pp.292-312.

CRAGIN, K. R. «The November 2015 Paris Attacks: The impact of Foreing Fighter Returnees», Orbis, Spring, 2017, pp.1-15.

Cumming-Bruce, N. «Horrid Conditions in Syria Camp Where ISIS Families Fled Risk Fostering Extremism», The New York Times, 11 de septiembre de 2019, Disponible en [fecha de consulta: 21 de mayo de 2019] https://www.nytimes.com/2019/09/11/world/middleeast/syriacamp-isis-families-islamic-state-extremism.html.

Cuthbertson, I. M. «Prisons and the Education of Terrorist», World Policy Journal, 3, 2004, pp.15-22

De La Corte IbÁÑEZ, L. «Un califato sin territorio ni califa. Vida y muerte de Bagdadi y sus consecuencias para el futuro del Daesh y la yihad global», Instituto Español de Estudios Estratégicos, Documento Marco 13/2019, 2019, pp.1-30.

De Miguel, R. «La muerte del bebé de una británica del ISIS desata las críticas al Gobierno», El País, 10 de marzo de 2019, Disponible en 
[fecha de última consulta: 20 de mayo de 2020] https://elpais.com/ internacional/2019/03/09/actualidad/1552138934_514792.html.

DEARDEN, L. "Only one in 10 jihadis returning from Syria prosecuted, figures reveal», Independent, 21 de febrero de 2019, Disponible en [fecha de última consulta: 10 de junio de 2020] https://www.independent.co.uk/news/uk/home-news/shamima-begum-isis-return-uk-syriajihadis-terror-threat-prosecute-nationality-a8790991.html.

Del Rosal Blasco, B. "¿Hacía un Derecho penal de la postmodernidad?», Revista Electrónica de Ciencia Penal y Criminología, 11(08), 2009, pp.1-64.

DíEz Ripollés, J. L. «El nuevo modelo penal de la seguridad ciudadana». Revista Electrónica de Ciencia Penal y Criminología, 6(03), 2004, pp.134.

Directiva (Ue) 2017/541 Del Parlamento Europeo Y Del Consejo De 15 De Marzo De 2017 Relativa A La Lucha Contra El Terrorismo.

DworkIN, A. «Beyond Good and Evil: Why Europe Should bring ISIS Foreing Fighters Home», European Council on Foreing Relations, Policy Brief, Octubre 2019, pp.1-20.

EURONEws. "Belgian and UK authorities say ISIS fighters should face justice in Iraq and Syria», Euronews, 3 de noviembre de 2019, Disponible en [fecha de última consulta: 10 de junio de 2020] https://www. euronews.com/2019/11/02/turkey-will-send-its-jihadist-prisonershome-amid-anger-with-europe.

EUROPA PRESS. «Trump amenaza con liberar a los miembros europeos de Estado Islámico si no son repatriados», Europa Press, 21 de agosto de 2019, Disponible en [fecha de consulta: 21 de mayo de 2020] https://www.europapress.es/internacional/noticia-trump-amenaza-liberar-miembros-europeos-estado-islamico-si-no-son-repatriados-20190821233330.html.

European Parliamentary Research SERvice. "The return of foreing fighters to EU soil. Ex-post evaluation», European Parliament, Study, 2018.

Europol. "European Union Terrorism Situation and Trend Report 2019», European Union Agency for Law Enforcement Cooperation», 2019.

FERNÁNDEZ ABAD, C. «La doble problemática del terrorismo yihadista en prisión: una aproximación crítica a la respuesta del sistema penitenciario español», Indret. Revista para el análisis del Derecho, 3, 2020, pp. 319-339.

FERRAJOLI, L. «Guerra y terrorismo internacional. Un análisis del lenguaje jurídico», Anuario Mexicano de Derecho Internacional, vol. IX, 2009, pp. 13-33. 
GaLl, C. «Turkey Vows to Send ISIS Militants Home», The New York Times, 8 de noviembre de 2019, Disponible en [fecha de última consulta: 21 de mayo de 2020] https://www.nytimes.com/2019/11/08/world/ middleeast/turkey-syria-isis-prisoners.html.

García-CALVO, C. "No hay vida sin yihad y no hay yihad sin hégira: la movilización yihadista de mujeres en España, 2014-2016», Real Instituto Elcano, ARI 28/2017, 2017, pp.1-15.

GARLAND, D. La cultura del control. Crimen y Orden Social en la sociedad contemporánea. Barcelona, Gedisa, 2005.

GarRIDO MuÑoz, A. «Un nuevo cortocircuito legislativo en Naciones Unidas: la Resolución 2178 (2014) del Consejo de Seguridad de Naciones Unidas relativa a los combatientes terroristas extranjeros», Revista Española de Derecho Internacional, núm. 67, pp. 303-307.

GIL GIL, A., «La expansión de los delitos de terrorismo en España a través del delito de pertenencia a organización terrorista», en Ambos, K., Malarino, E. y Steiner, C. (coords), Terrorismo y Derecho Penal, Bogotá, 2015, Konrad Adenauer, pp. 331-364. Disponible en [fecha de última consulta 20 de junio de 2020]: https://www.kas. de/c/document_library/get_file?uuid=bb9ce34a-d4a0-2600-3bc3510ae89ef7ab\&groupId=252038.

Gladstone, R. «German ISIS Member Who Denied Killing is Charged in Murders", The New York Times, 3 de junio de 2017, Disponible en [fecha de última consulta: https://www.nytimes.com/2017/01/03/world/ europe/harry-sarfo-isis-germany.html].

GobIERno De EsPaÑA. Estrategia Nacional contra el Terrorismo. Madrid, Ministerio de la Presidencia, Relaciones con las Cortes e Igualdad, 2019.

Gómez IsA, F. «Los ataques armados con drones en Derecho Internacional», Revista Española de Derecho Internacional, vol.67/1, 2015, pp.61-92.

Gouttefarde, F. «L'invocation de l'article 42.7 TUE ou la solidariste militaire européenne à l'épreuve de la guerre contre le terrorismo», Revue generale de droit international public, Vol. 129, núm. 1, 2016, pp. 51-67.

GutiÉRrez, J. A., Jordán, J. Y Trujillo, H. «Prevención de la radicalización yihadista en las prisiones españolas. Situación actual, retos y disfunciones del sistema penitenciario español», Athena Intelligence Journal, 1, 2008, pp.1.10.

Hegghammer, T. «Should I Stay or Should I Go? Explaining Variation in Western Jihadist' Choice between Domestic and Foreing Fighting», American Political Science Review, vol.107, núm.1, 2013, pp.1-15. 
Hegghammer, T. y Nesser, P. «Assessing the Islamic State's Commitment to Attacking the West», Perspectives on Terrorism, vol.9, núm.4, 2015, pp.14-30.

HoffMAN, A. y Furlan, M. «Challenges posed by returning foreing fighters», Program on Extremist. The George Washington University, 2020, p.15.

Holman, T. «Belgian and French Foreing Fighters in Iraq 2003-2005: A Comparative Case Study», Studies in Conflict and Terrorism, 2015, pp.1-19.

HoRgan, J. «Deradicalization or Disengagment? A process in need of clarity and a Counterterrorism initiative in need of evaluation», Perspectives on Terrorism, vol.2, núm.4, 2008, pp.1-5.

HoRgan, J. y Braddock, K. «Rehabilitating the Terrorist? Challenges in Assessing the Effectiveness of Deradicalization Programs», Terrorism and Political Violence, 22:2, pp.267-291.

Hurtado, L. M. «Los kurdos quieren que un tribunal internacional juzgue al Estado Islámico», El Mundo, 26 de marzo de 2019, Disponible en [fecha de última consulta: 11 de junio de 2020] https://www.elmundo.es/internacional/2019/03/26/5c9a4fac21efa0f0168b4659.html.

Igualada Tolosa, C. «La radicalización yihadista en el entorno de las prisiones», Instituto Español de Estudios Estratégicos, Documento de Opinión, 2017, pp. 3-7.

JAGER, A. "The «shoe bomber» Richard Reid. His radicalization explained», International Institute for Counter-Terrorism, 2018, pp.1-14.

Jakobs, G. y Cancio Melía, M. Derecho Penal del Enemigo, Madrid, Civitas, 2006.

Jenkins, B. M. «Options for Dealing with Islamic State Foreing Fighters Currently Detained in Syria», CTC SENTINEL, vol.12, núm.5, pp.1123.

Jiménez García, F. «Combatientes Terroristas Extranjeros y conflictos armados: utilitarismo inmediato ante fenómenos no resueltos y normas no consensuadas», Revista Española de Derecho Internacional, vol.62/2, 2016, pp.277-301.

KoEHLER, D. Understanding Deradicalization. Methods, tools and programs for countering violent extremism, New York, Routledge, 2017.

LAMARCA PÉREZ, C. "Legislación antiterrorista: la normalización de la excepcionalidad», Jueces para la Democracia, núm.88, 2017, pp.39-55.

LóPEz-FonsecA, O. «Agentes españoles colaboran en Siria en una operación de EEUU para identificar yihadistas europeos», El País, 4 de marzo de 2019, Disponible en [fecha de última consulta: 29 de mayo de 2020] https://elpais.com/politica/2019/03/03/actualidad/1551607296_074638.html. 
Macaskill, E. «May defends use of drones to kill British terrorist overseas», The Guardian, 20 de diciembre de 2017, Disponible en [fecha de última consulta: 20 de mayo de 2020] https://www.theguardian. com/world/2017/dec/20/theresa-may-drone-strikes-british-terroristsreyaad-khan.

MaLET, D. «The European Experience with Foreing Fighters and Returnees», en RENARD, T. y COOLSAET, R. (Eds.), Returnees: Who Are They, Why Are They (Not) Coming Back and How Should We Dealt with Them, Egmont Paper, núm.101, 2018. p.14.

Malet, D. y Hayes, R. «Foreing Fighter Returnees: An Indefinite Threat?» Terrorism and Political Violence, 2018, pp.1-19.

Malet, D. (2015). «Foreing Fighter Moblization And Persistence In A Global Context», Terrorism and Political Violence, pp.1-20.

Marrero Rocha, I. «Los combatientes «terroristas» extranjeros de la Unión Europea a la luz de la Resolución 2178 (2014) del Consejo de Seguridad de Naciones Unidas», Revista de Derecho Comunitario Europeo, núm.54, pp.555-594.

MARTinez, S. «Europa esquiva la repatriación de los hijos de los yihadistas», El Periódico, 17 de noviembre de 2019, Disponible en [fecha de última consulta: 22 de junio de 2020] https://www.elperiodico.com/es/ internacional/20191115/europa-calla-frente-a-la-repatriacion-de-loshijos-de-los-yihadistas-europeos-7737692.

MehrA, T. «Bringing (Foreing) Terrorist Fighters to Justice in a Post-Isis Landscape Part III: Collecting Evidence from Conflict Situations», International Centre for Counter-Terrorism- The Hague, 12 de junio de 2018, Disponible en [fecha de última consulta: 28 de mayo de 2020] https://icct.nl/publication/bringing-foreign-terrorist-fighters-to-justice-in-a-post-isis-landscape-part-iii-collecting-evidence-from-conflictsituations/.

MEHRA, T. «European countries are being challenged in court to repatriate their foreing fighters and families», International Centre for Counter-Terrorism - The Hague, Disponible en [fecha de última consulta: 21 de mayo de 2020] https://icct.nl/publication/european-countriesare-being-challenged-in-court-to-repatriate-their-foreign-fighters-andfamilies/.

MenrA, T. y Paulussen, C. «The Repatriation of Foreing Fighters and Their Families: Options, Obligations, Morality and Long-Term Thinking», International Centre for Counter-Terrorism - The Hague, 2019, Disponible en [fecha de última consulta: 21 de mayo de 2020] https:// icct.nl/publication/the-repatriation-of-foreign-fighters-and-their-families-options-obligations-morality-and-long-term-thinking/. 
MIR PUIG, S. «Principio de proporcionalidad y fines del derecho penal», en Echano Basaldúa, J.I, Estudios jurídicos en memoria de José María Lidón, 2002, pp. 349-366, Universidad de Deusto.

Nistal BuRóN, J. «Radicalización en prisión», en (Bermejo Casado, R. y Bazaga Fernández, I. eds.) Radicalización violenta en España. Detección, gestión y respuesta (pp.121-131), Tirant lo Blanch, Valencia, 2019.

NÚÑEz CASTAÑo, E. «Algunas consideraciones sobre la transposición al Derecho Penal español de la Directiva 2017/541/UE del Parlamento europeo y del Consejo, en materia de terrorismo: ¿una tarea necesaria?», en González Cano, M.I. (dir.), Integración europea y justicia penal (pp. 229 -277), Tirant lo Blanch, Valencia, 2018.

OsCE. «Repatriation of foreing terrorist fighters and their families urgently needed to safeguard human rights and security, OSCE human right head says», Organization for Security and Co-operation in Europe», Disponible en [fecha de consulta: 18 de junio de 2020] https:// www.osce.org/odihr/445909.

PaRedes Castañón, J.m. «Una modesta proposición para derogar los delitos de terrorismo (o casi)», en Pérez Cepeda, A.I./Portilla Contreras, G. (dir), Terrorismo y contraterrorismo en el siglo XXI. Un análisis penal y político criminal, España, 2016, edit. Ratio Legis, pp. 61 - 86.

Paredes Castañón, J, M. «Terrorismo y principio de intervención mínima: una propuesta de despenalización», En Alonso Rimo, A., Cuerda Arnau, M. L. Y Fernández Hernández, A. (Dir.), Terrorismo, sistema penal y derechos fundamentales (pp.63-94), Valencia, Tirant lo Blanch, 2018.

Paulussen, C. y Pitcher, K. «Prosecuting (Potential) Foreing Fighter: Legislative and Practical Challenge», International Centre for CounterTerrorism- The Hague, ICCT Research Paper, 2018, pp.1-49.

Pérez CEPEDA, A. I. El pacto antiyihadista: criminalización de la radicalización, Salamanca, Tirant lo Blanch, 2017.

PoKalova, E. Returning Islamist Foreing Fighters. Threats and Challenges to the West, Switzerland, Palgrave Macmillan, 2020.

Qureshi, A. Blowback - Foreign Fighters and the Threat They Pose. Londres: Cage, 2014.

Radicalisation AWERENESS Network. «Ran Manual. Responses to Returnees: Foreing terrorist fighters and their families», RAN, 2017.

ReEd, A., Van ZuijdewiJn, R. y BaKKeR, E. «Pathways of Foreing Fighters: Policy Options and Their (Un)Intended Consequences», International Centre for Counter-Terrorism-The Hague, ICCT Policy Brief, 2015, pp.1-19. 
REINARES, F. "Yihadistas retornados tras desplazarse de España a Siria e Irak: ¿qué motivos tienen?, ¿dónde están ahora?, ¿suponen un peligro», Real Instituto Elcano, Comentario Elcano 50/2018, 2018, pp.1-3.

Reinares, F., García-Calvo, C. y Vicente, A. Yihadismo y yihadistas en España. Quince años después del 11-M, Real Instituto Elcano, Madrid, 2019.

RENARD, T. «How to handle returning foreing fighters: policies and challenges», European Parliament, 2018.

Renard. T. y Coolsaet, R. «Losing Control Over Returnees?», Lawfare, Foreing Policy Essay, 2019, Disponible en [fecha de última consulta: 21 de mayo de 2020] https://www.lawfareblog.com/losing-controlover-returnees.

REUTERS. "France snubs Trump's appeal to repatriate IS fighters en masse, for now», Reuters, 18 de febrero de 2019, Disponible en [fecha de última consulta: 10 de junio de 2020] https://www.reuters.com/ article/us-mideast-crisis-syria-france/france-snubs-trumps-appeal-torepatriate-is-fighters-en-masse-for-now-idUSKCN1Q70KV.

Rubin, A. J. «France Hands ISIS Suspects to Iraq, Which Sentences Them to Hang», The New York Times, 29 de mayo de 2019, Disponible en [fecha de consulta: 5 de junio de 2020] https:/www.nytimes. com/2019/05/29/world/middleeast/france-iraq-isis-trials.html.

Rushchenko, J. «Terrorist recruitment and prison radicalization: Assessing the UK experiment of separation centres», European Journal of Criminology, Special Issue: Understanding European Jihadist: criminal, extremist or both, 2019, pp.1-20.

SALINAS De FríAs, A. «Lucha contra el terrorismo internacional. No solo del uso de la fuerza pueden vivir los Estados», Revista española de derecho internacional, vol. 68, núm. 2, 2016, pp. 229-252.

SANCHA, N. «La ofensiva turca en Siria desata el miedo a la evasión de los yihadistas detenidos por los kurdos», El País, 11 de octubre de 2019, Disponible en [fecha de última consulta: 11 de junio de 2020] https:// elpais.com/internacional/2019/10/10/actualidad/1570731504_715651. html.

ScHMID, A. «Foreing (Terrorist) Fighters Estimates: Conceptual and Data Issues», International Centre for Counter-Terrorism-The Hague, 2015, pp.3-6.

SILKE, A. «Terrorist, extremist and prison: an introduction to the critical issues», en (Silke, A. ed.), Prisons, Terrorism and Extremism. Critical Issues in Management, Radicalisation and Reform, Routledge, Londres, 2014.

Silke, A. y VeldhuIs, T. "Countering Violent Extremism in Prisons: a review of key recent research and critical research gaps», Perspectives on Terrorism, 5, 2017, pp.2-11. 
SILVA SÁNCHEZ, J.M. "Asesinatos selectivos en la «guerra punitiva» contra el terrorismo», InDret. Revista de Análisis para el Derecho, núm.1, 2017, pp.1-19.

Tамміко, T. «The Threat of Returning Foreing Fighters: Finnish State Responses to the Volunteers in the Spanish and Syria-Iraq Civil Wars», Terrorism and Political Violence, 2018, pp.1-18.

TRANSPARENCY INTERNATIONAL. «Corruption Perceptions Index», Transparency International, Disponible en [fecha de última consulta: 8 de junio de 2020] https://www.transparency.org/es/cpi/2019/results/irq.

VIDINO, L. «European foreing fighters in Syria: dynamics and responses», European View, núm.13, pp.217-224.

\section{Fuentes normativas internacionales}

- Resolución 2178 (2014) De 24 De Septiembre De 2014, S/Res/2178

- Resolución 2178 (2014) De 24 De Septiembre De 2014, S/Res/2178.

- Resolución 2253 (2015) De 17 De Diciembre De 2015, S/Res/2253.

- Resolución 2396 (2017) De 21 De Diciembre De 2017, S/Res/2396. 
